\title{
Health potential of polyols as sugar replacers, with emphasis on low glycaemic properties
}

\author{
Geoffrey Livesey \\ Independent Nutrition Logic, Pealerswell House, Wymondham, Norfolk NR18 OQX, UK
}

\begin{abstract}
Polyols are hydrogenated carbohydrates used as sugar replacers. Interest now arises because of their multiple potential health benefits. They are non-cariogenic (sugar-free tooth-friendly), lowglycaemic (potentially helpful in diabetes and cardiovascular disease), low-energy and lowinsulinaemic (potentially helpful in obesity), low-digestible (potentially helpful in the colon), osmotic (colon-hydrating, laxative and purifying) carbohydrates. Such potential health benefits are reviewed. A major focus here is the glycaemic index (GI) of polyols as regards the health implications of low-GI foods. The literature on glycaemia and insulinaemia after polyol ingestion was analysed and expressed in the GI and insulinaemic index (II) modes, which yielded the values: erythritol 0,2 ; xylitol 13,11 ; sorbitol 9, 11; mannitol 0,0 ; maltitol 35,27 ; isomalt 9, 6; lactitol 6, 4; polyglycitol 39, 23. These values are all much lower than sucrose 65,43 or glucose 100,100 . GI values on replacing sucrose were independent of both intake (up to $50 \mathrm{~g}$ ) and the state of carbohydrate metabolism (normal, type 1 with artificial pancreas and type 2 diabetes mellitus). The assignment of foods and polyols to GI bands is considered, these being: high (> $70)$, intermediate $(>55-70)$, low $(>40-55)$, and very low $(<40)$ including non-glycaemic; the last aims to target particularly low-GI-carbohydrate-based foods. Polyols ranged from low to very low GI. An examination was made of the dietary factors affecting the GI of polyols and foods. Polyol and other food GI values could be used to estimate the GI of food mixtures containing polyols without underestimation. Among foods and polyols a departure of II from GI was observed due to fat elevating II and reducing GI. Fat exerted an additional negative influence on GI, presumed due to reduced rates of gastric emptying. Among the foods examined, the interaction was prominent with snack foods; this potentially damaging insulinaemia could be reduced using polyols. Improved glycated haemoglobin as a marker of glycaemic control was found in a 12-week study of type 2 diabetes mellitus patients consuming polyol, adding to other studies showing improved glucose control on ingestion of low-GI carbohydrate. In general some improvement in long-term glycaemic control was discernible on reducing the glycaemic load via GI by as little as 15-20 g daily. Similar amounts of polyols are normally acceptable. Although polyols are not essential nutrients, they contribute to clinically recognised maintenance of a healthy colonic environment and function. A role for polyols and polyol foods to hydrate the colonic contents and aid laxation is now recognised by physicians. Polyols favour saccharolytic anaerobes and aciduric organisms in the colon, purifying the colon of endotoxic, putrefying and pathological organisms, which has clinical relevance. Polyols also contribute towards short-chain organic acid formation for a healthy colonic epithelium. Polyol toothfriendliness and reduced energy values are affirmed and add to the potential benefits. In regard to gastrointestinal tolerance, food scientists and nutritionists, physicians, and dentists have in their independent professional capacities each now described sensible approaches to the use and consumption of polyols.
\end{abstract}

Diabetes; Coronary heart disease; Caries; Laxation; Digestive health; Glycaemic index; Insulinaemic index; Food energy; Sucrose; Sucrose replacer; Polyol; Erythritol; Xylitol; Sorbitol; Mannitol; Maltitol; Isomalt; Lactitol; Polyglycitol

\footnotetext{
Abbreviations: DM, diabetes mellitus; FPG, fasting plasma glucose; GI, glycaemic index; GL, glycaemic load; GT, glucose tolerance; $\mathrm{HbA}_{1 \mathrm{c}}$, glycated or glycosylated haemoglobin; II, insulinaemic index; RIR, relative insulin response.

Corresponding author: Dr G. Livesey, fax +44 1953 600218, email glivesey@inlogic.co.uk
} 


\section{Introduction}

Although polyols (hydrogenated carbohydrates) have been reviewed from various perspectives (Wang \& van Eys, 1981; Ziesenitz \& Siebert, 1987; Dills, 1989; Livesey, 1992, 2001; Zumbé et al. 2001) no reviews have considered their glycaemic indices (GI) and there has been little consideration of their prospects in respect of the health of the digestive tract other than their role in caries prevention. GI ranks foods and carbohydrates according to their ability to raise the concentration of glucose in the blood (Jenkins et al. 1981). Also the overall glycaemic load (GL) from the diet has implications for the development and management of metabolic syndrome, diabetes, and CHD and the control of metabolic markers such as glycated proteins (glycated haemoglobin $\left(\mathrm{HbA}_{1 \mathrm{c}}\right)$, fructosamine), plasma triacylglycerols, HDL and sensitivity to insulin (Brand et al. 1991; European Association for the Study of Diabetes, 1995, 2000; Salmerón et al. 1997a,b; Food and Agriculture Organization, 1998; Frost et al. 1998, 1999; Bär, 2000; Bastyr et al. 2000; Buyken et al. 2000, 2001; Canadian Diabetes Association, 2000; Diabetes UK, 2000, 2002; Liu et al. 2000a,b; Stratton et al. 2000; Bellisle, 2001; Ford \& Liu, 2001; Gilbertson et al. 2001; Kapur \& Kapur, 2001; Khaw et al. 2001; International Diabetes Institute Australia, 2002; Jenkins et al. 2002; Livesey, 2002a).

Widespread knowledge of the GI concept largely postdates many relevant studies on polyols and those studies having reported the GI of polyols have sometimes used calculation methods that are no longer acceptable. These studies are revisited to place information available in a modern context. The multiple potential health benefits from using polyols as replacers of sugars, maltodextrins and glucose syrups or in laxation are examined under the concepts of glycaemia and insulinaemia, reduced energy, caries reduction, and digestive health. The review begins with background on the definition, description and metabolism of polyols.

\section{Polyols \\ Definition of 'polyol'}

'Sugar replacer', 'sugar alcohol', 'hydrogenated carbohydrate', and 'polyol' are synonyms for a sub-class of carbohydrates present in foods. The defining characteristic is the occurrence of an alcohol group $(>\mathrm{CH}-\mathrm{OH})$ in place of the carbonyl group $(>\mathrm{C}=\mathrm{O})$ in the aldose and ketose moieties of mono-, di-, oligo- and polysaccharides; hence polyols are not sugars, and generally carry the suffix '-itol' in place of the suffix '-ose' according to modern carbohydrate nomenclature (McNaught, 1996). The name 'polyol' is an abridgement of 'polyalcohol' or 'polyhydric alcohol'. Preferred names are 'polyol' or 'hydrogenated carbohydrate'; the latter makes explicit that these substances are carbohydrate. Individual polyols are described in Table 1 and in more detail later (p. 164).

\section{Classification amongst other carbohydrates}

Because polyols are not sugars they are permitted in sugarfree and tooth-friendly products (European Communities,
1994). The distinction between sugars and polyols is important yet frequently overlooked, the consultation by the Food and Agriculture Organization (1998) being the most significant recent example. Sugars are legally defined for nutrition labelling purposes as mono- and disaccharide only. In contrast, polyols may be hydrogenated mono-, di-, but also oligo- and polysaccharide (Table 2). Polyols also contribute unavailable carbohydrate to fermentation analogous to dietary fibre to which it may contribute (American Association of Cereal Chemists, 2001). Examples of named carbohydrates in each subclass of food carbohydrates are given in Table 2 to help show their difference from polyols. The overall order in which the carbohydrates are listed here is governed by molecular weight or degree of polymerisation, as suggested by the Food and Agriculture Organization (1998). However, no real physiological meaning can be attached to this order, nor does this order help interpretation of carbohydrate terminology in regulatory food codes. To be usefully informative the nutrition information panel will in future require other information; in this context the GI, GL (GI $\times$ amount of carbohydrate) and other possible expressions of glycaemic potential are candidates for possible inclusion in future food labelling and food tables.

\section{Individual polyols: description, absorption and metabolism}

The physiological attributes of polyols, i.e. low cariogenicity, low glycaemia, low insulinaemia, low energy value, source of substrate for a healthy colon and intestinal tolerance are linked through the common property of polyols being difficult to digest or slow to metabolise yet relatively easy to ferment in the colon. This property results from the hindrance to digestion and absorption by the alcohol group that replaces the carbonyl group and the occurrence of saccharide linkages other than the $\alpha 1-4$ and $\alpha 1-6$ present in starches and sucrose. Thus, a low digestibility and/or slow hepatic glucose release is the determinant of their low glycaemic and insulinaemic response properties.

During the time polyols are resident in the mouth, they resist fermentation and acidogenesis by the micro-organisms of dental plaque (Willibald-Ettle \& Schiweck, 1996; Kandelman, 1997) and are not absorbed via the stomach to any significant degree. Absorption that does occur is by passive diffusion of monosaccharide polyol along a concentration gradient (Herman, 1974). Disaccharide and higher polyols are too large to diffuse from the gut into the circulation in amounts more than $2 \%$ of oral intake (Livesey, 1992). Some di-, oligo- and polysaccharide polyols may liberate glucose, but as their digestion is slow and incomplete this does not result in a substantial rise in blood glucose, as will be shown in later sections (p. 168). The small intestine is probably less permeable distally so that co-released monosaccharide polyol may be less readily absorbed than the same monosaccharide polyol taken orally. Once absorbed, monosaccharide polyols are excreted via the kidneys, oxidised directly or converted to glycogen or glucose in the liver; the route of metabolism and excretion depends on their structure. Unabsorbed carbohydrate from polyols is generally fermented completely by the colonic microflora (Livesey, 1992). 
Table 1. Polyol specifications

\begin{tabular}{|c|c|c|c|c|c|c|}
\hline Polyol & Formula & $\begin{array}{l}\text { Saccharide } \\
\text { type }\end{array}$ & Generic form & $\begin{array}{l}\text { Molecular } \\
\text { weight }(\mathrm{Da})\end{array}$ & Synonyms* & Further details \\
\hline Erythritol & $\mathrm{C}_{4} \mathrm{H}_{10} \mathrm{O}_{4}$ & Mono- & Tetritol & $122 \cdot 12$ & $\begin{array}{l}\text { Hydrogenated erythrose } \\
\text { meso-Erythritol } \\
\text { Erthrite } \\
\text { tetra-Hydroxybutane } \\
1,2,3,4-B u t a n e t e t r o l \\
\text { Erythrol } \\
\text { Physitol }\end{array}$ & FNP 52/7 \\
\hline Mannitol & $\mathrm{C}_{6} \mathrm{H}_{14} \mathrm{O}_{6}$ & Mono- & Hexitol & $182 \cdot 17$ & $\begin{array}{l}\text { Hydrogenated mannose } \\
\text { D-Mannitol } \\
\text { Mannite }\end{array}$ & FMP 52/4 \\
\hline Sorbitol & $\mathrm{C}_{6} \mathrm{H}_{14} \mathrm{O}_{6}$ & Mono- & Hexitol & $182 \cdot 17$ & $\begin{array}{l}\text { Hydrogenated glucose } \\
\text { D-Sorbitol } \\
\text { Glucitol } \\
\text { Sorbol } \\
\text { Sorbit }\end{array}$ & FNP 52/4 \\
\hline Lactitol & $\mathrm{C}_{12} \mathrm{H}_{24} \mathrm{O}_{11}$ & $\mathrm{Di}-$ & \multicolumn{2}{|c|}{$\begin{array}{l}\text { Hexopyranosyl- } 344 \cdot 3 \\
\text { hexitol }\end{array}$} & $\begin{array}{l}\text { Hydrogenated lactose } \\
\beta \text {-D-Galactopyranosyl-1-4-D-sorbitol } \\
\beta \text {-D-Galactopyranosyl-1-4-D-glucitol } \\
\text { Lactositol } \\
\text { Lactit } \\
\text { Lactosbiosit }\end{array}$ & FNP 52/4 \\
\hline Isomalt & $\mathrm{C}_{12} \mathrm{H}_{24} \mathrm{O}_{11}$ & Mixed di- & \multicolumn{2}{|c|}{$\begin{array}{l}\text { Hexopyranosyl- } 344 \cdot 3 \\
\text { hexitol }\end{array}$} & $\begin{array}{l}\text { Hydrogenated isomaltulose } \\
\text { Hydrogenated palatinose } \\
\text { Mixture of } \alpha \text {-D-glucopyranosyl-1-6-D-sorbitol } \\
\quad \text { and } \alpha \text {-D-glucopyranosyl-1-1-D-mannitol }\end{array}$ & FNP 52/4 \\
\hline Polyglycitol & \multicolumn{4}{|c|}{$\begin{array}{l}\text { Mixed, }<50 \% \text { di- and of other especially oligo- and } \\
\text { polysaccharides } \ddagger\end{array}$} & $\begin{array}{l}\text { Polyglucitol } \\
\text { Hydrogenated starch hydrolysate }\end{array}$ & FNP 52/6 \\
\hline
\end{tabular}

FNP 52, Food and Nutrition paper 52.

* Excluding proprietary names.

† Food and Agriculture Organization (1996-1999), addenda 4-7.

$\ddagger$ For details, see p. 167.

Representative values for the absorption, fermentation and urinary excretion of polyols are shown in Table 3 . The data are drawn from information collected by Livesey (1992), the Life Sciences Research Office (1994, 1999), and other material described later (pp. 166-168). For the present, no distinction is made between the results of digestibility studies assessing absorption from liquids and solids on the ground that such distinctions at moderate polyol intake are based on invasive methodology in which solids may increase the non-recovery of polyols at the ileum by increasing retention in the stomach and upper gastrointestinal tract rather than increasing absorption. Differences in the tolerance of polyols when consumed in liquid and solid meals are ascribable to different rates of stomach emptying rather than differences in the extent of digestion and absorption (Livesey, 1990a, 2001). Excessive intake might cause absorption to be lowered and potentially would affect the glycaemic response to polyols, though, as will be seen in subsequent dose-response data (p. 169), this appears not to happen. 
Table 2. Classification of the major carbohydrates in foods (modified from Food and Agriculture Organization, 1998)

\begin{tabular}{|c|c|c|c|}
\hline Class & DP & Sub-class & Examples \\
\hline Monosaccharides & 1 & $\begin{array}{l}\text { Sugars } \\
\text { Hydrogenated monosaccharides }\end{array}$ & $\begin{array}{l}\text { Glucose, fructose, galactose } \\
\text { Erythritol, xylitol, mannitol, sorbitol }\end{array}$ \\
\hline Disaccharides & 2 & $\begin{array}{l}\text { Sugars } \\
\text { Hydrogenated disaccharides }\end{array}$ & $\begin{array}{l}\text { Sucrose, maltose, lactose, trehalose } \\
\text { Maltitol, isomalt, lactitol }\end{array}$ \\
\hline Oligosaccharides & $3-9$ & $\begin{array}{l}\text { Malto-oligosaccharides } \\
\text { Other oligosaccharides } \\
\text { Hydrogenated oligosaccharides }\end{array}$ & $\begin{array}{l}\text { Maltodextrins. } \\
\text { Raffinose, stachyose, fructo-oligosaccharides, } \\
\text { galacto-oligosaccharides. } \\
\text { Hydrogenated starch hydrolysate }\end{array}$ \\
\hline Polysaccharides & $>9$ & $\begin{array}{l}\text { Starch } \\
\text { NSP } \\
\text { Hydrogenated polysaccharides }\end{array}$ & $\begin{array}{l}\text { Amylose, amylopectin, modified starches } \\
\text { Cellulose, hemicelluloses, pectins, etc } \\
\text { Polyglycitol, hydrogenated polydextrose }\end{array}$ \\
\hline
\end{tabular}

$\mathrm{DP}$, degree of polymerisation.

Table 3. Approximate absorption, fermentation and urinary excretion of polyols*

\begin{tabular}{|c|c|c|c|}
\hline & Absorption (g/100 g) & Fermentation $(\mathrm{g} / 100 \mathrm{~g})$ & Urinary excretion $(\mathrm{g} / 100 \mathrm{~g})$ \\
\hline Erythritol & 90 & 10 & 90 \\
\hline Xylitol & 50 & 50 & $<2$ \\
\hline Sorbitol & 25 & 75 & $<2$ \\
\hline Mannitol & 25 & 75 & 25 \\
\hline Isomalt & 10 & 90 & $<2$ \\
\hline Lactitol & 2 & 98 & $<2$ \\
\hline Maltitol & 40 & 60 & $<2$ \\
\hline \multicolumn{4}{|l|}{ Maltitol syrup } \\
\hline Regular, intermediate, high & about $50 \dagger$ & about $50 \dagger$ & $<2$ \\
\hline High-polymer & about $40 \ddagger$ & about $60 \ddagger$ & - \\
\hline Polyglycitol & about $40 \dagger$ & about $60 \dagger$ & $<2$ \\
\hline
\end{tabular}

Erythritol. This small (four-carbon, tetritol) molecule is absorbed readily by diffusion, with approximately $10 \%$ escaping to the large intestine in man (Oku \& Noda, 1990; Noda et al. 1994; Bornet et al. 1996a). Absorbed erythritol distributes widely through the tissues but its metabolism is minimal and being poorly reabsorbed via the kidneys it is essentially excreted unused in urine (Bernt et al. 1996).

Xylitol. Absorption of xylitol from the small intestine occurs less readily than the smaller molecule erythritol, causing more to be fermented in the large bowel. Estimates of the extent of fermentation range from 50 to $75 \%$ (Livesey, 1992; Life Sciences Research Office, 1994) with the lower value being more consistent with the size of this molecule. Thus, based on D-arabitol as a non-metabolisable marker of pentitol absorption, a similar absorption of oral xylitol in man would suggest it to be $53 \%$ (Bär, 1990). This is corroborated by the present author who has predicted its absorption based on molecular weight for a series of polyols (glycerol, erythritol, mannitol and lactitol) to be $48 \%$ (see Livesey, 1992). On the basis of energy values for xylitol proposed by several experts and authorities, absorbability by consensus is $49 \%$; this being the average of values esti- mated by the Dutch Nutrition Council (1987), Bär (1990), Bernier \& Pascal (1990), Livesey (1992); Life Sciences Research Office (1994), and Brooks (1995). The liver readily sequesters absorbed xylitol where it is dehydrogenated by a non-specific cytoplasmic NAD-dependent dehydrogenase (synonyms iditol dehydrogenase; polyol dehydrogenase). The xylulose so produced is phosphorylated via a specific xylulokinase to xylulose-5-phosphate, an intermediate of the pentose-phosphate pathway before conversion to glucose, which is only slowly released into the bloodstream or stored as glycogen (Keller \& Froesch, 1972).

Mannitol. Various forms of evidence indicate that approximately $25 \%$ of oral mannitol in solution is absorbed (reviewed in Livesey, 1992). Absorbed mannitol is excreted in urine because it is virtually non-metabolisable in the tissues (Nasrallah \& Iber, 1969) and the remainder or unabsorbed mannitol is slowly fermented.

Sorbitol. Estimates of absorption from oral solutions range from 25 to $80 \%$ of the ingested dose (Beaugerie et al. 1990; Livesey, 1992), with the lower value being 
more consistent with the size of this molecule (Livesey, 1992) and the higher value possibly due to the use of invasive methodology and non-recovery. Slow and late ${ }^{14} \mathrm{CO}_{2}$ excretion from labelled sorbitol (compared with glucose) in non-invasive studies in human subjects suggests lower absorption (Tsuji et al. 1990) though this could also be due to the temporal storage of $\left[{ }^{14} \mathrm{C}\right]$ carbon as glycogen. Absorbed sorbitol is practically metabolised fully as only a trace is excreted (Adcock \& Grey, 1957). Dehydrogenation in the liver is via the non-specific cytoplasmic NAD-dependent dehydrogenase, as for xylitol, with the production of fructose then glycogen or glucose that may be slowly released into the bloodstream. Unabsorbed sorbitol is extensively fermented to short-chain organic acids and gases (Hyams, 1983), with a considerable yield of butyric acid in vitro (Mortensen et al. 1988; Clausen et al. 1998).

Sorbitol syrup. The biological response to sorbitol syrup is based on the combined individual responses to its constituents, which are mainly sorbitol and mannitol (Table 1, see earlier; p. 166).

Maltitol. This is a disaccharide polyol (moieties of glucose and sorbitol; Table 1) for which hydrolysis is required before absorption. Absorption in human subjects is reported to range from 5 to $80 \%$ (Beaugerie et al. 1990; Life Sciences Research Office, 1999); the wide range is partly due to the use of invasive methods and partly due to the incorrect evaluation of results from non-invasive methods. Account needs to be taken of three non-invasive study approaches in human subjects. First, comparison of the time course of ${ }^{14} \mathrm{CO}_{2}$ production from $\left[\mathrm{U}^{14} \mathrm{C}\right]$ maltitol, $\left[\mathrm{U}^{14} \mathrm{C}\right]$ glucose (fully available) and $\left[\mathrm{U}^{14} \mathrm{C}\right]$ fructo-oligosaccharides (fully unavailable) (see data in Livesey, 1993) indicates by the simplest of computational models a lower limit to absorption of $35 \%$ for maltitol $(10 \mathrm{~g})$ in solution. Second, glycaemia and insulinaemia (see pp. 167-168) indicate a lower limit to absorption of 35 to $27 \%$ respectively formaltitol $(25-50 \mathrm{~g})$ in solution. Third, based on indirect calorimetry following the ingestion of a high-polymer maltitol syrup containing $50 \%$ maltitol and 50 $\%$ polymer and separate study of the polymer fraction (Sinaud et al. 2002) the energy value of maltitol can be estimated. This estimated energy value corresponds to maltitol absorption of approximately $32 \%$ when consumed in three mixed solid meals interspersed by three maltitol drinks (totalling $50 \mathrm{~g}$ maltitol in $50 \mathrm{~g}$ polymer daily). On the basis of energy values for maltitol proposed by several authorities, absorbability by consensus is $45 \%$ (Dutch Nutrition Council, 1987; Bär, 1990; Bernier \& Pascal, 1990; Life Sciences Research Office, 1994, 1999; Brooks, 1995; Australia New Zealand Food Authority, 2001; American Diabetes Association, 2002; Food and Agriculture Organization, unpublished results). The products of hydrolysis by intestinal brush-border disaccharidases are glucose and sorbitol, the metabolism of which has been described earlier (p. 166).
Maltitol $\operatorname{syrup}(s)$. These are hydrogenated starch hydrolysates and consist of a mixture of sorbitol, maltitol, and hydrogenated oligo- and polysaccharides (Table 1). The terminology 'regular-, intermediate- and higher-maltitol syrups and high-polymer maltitol syrup' is applied here to conveniently identify four distinctly different products, all of which bear the same general name 'maltitol syrup'. Information on the availability of carbohydrate from hydrogenated oligo- and polysaccharide fractions of regular, intermediate- and high-maltitol syrups is not evidently available. However, based on glycaemic and insulinaemic response data (derived later, see p. 169), it is probably close to $50 \%$.

A maltitol syrup comprising $50 \%$ maltitol and $50 \%$ hydrogenated polymer has recently been introduced (Sinaud et al. 2002), which here is referred to as 'highpolymer maltitol syrup'. The high-polymer fraction is obtained by heating starch at high temperature and low moisture in the presence of an acid catalyst, which yields after separation a product with an average degree of polymerisation of about 17, the introduction of 1-2 and 1-3 glucosidic linkages and so a proportion of branched linkages. Digestibility of the high-polymer maltitol syrup in vitro is about $40 \%$ based on hydrolysis with $\alpha$-amylase and amyloglucosidase and the release of sorbitol and glucose (Sinaud et al. 2002). This value is consistent with the glycaemia and insulinaemia described in the present review.

Polyglycitol syrup. Similar to the maltitol syrups this is a hydrogenated starch hydrolysate, though it has more sorbitol $(<20 v .<8 \%)$ and less maltitol $(<50 v . \geq 50 \%)$. The absorption of carbohydrate from polyglycitol syrup is uncertain in extent. However, with a GI and insulinaemic index (II) similar to those for maltitol (see pp. 169-171) it probably has a similar small-intestinal digestibility, at about $40 \%$.

Isomalt. This is a mixed disaccharide polyol (Table 1). The products of hydrolysis are glucose, sorbitol and mannitol, the metabolism of which is described earlier (p. 166). However, a variety of studies including non-invasive methods in human subjects and methods in animals (Livesey, $1990 a, b, 2000 a)$ together with the present studies on glycaemia and insulinaemia suggest 0 to $14 \%$ of isomalt is available as carbohydrate in man. On the basis of the energy values of isomalt suggested by various authorities and experts (Dutch Nutrition Council, 1987; Livesey, 1992; Life Sciences Research Office, 1994; Brooks, 1995) a consensus of approximately $90 \%$ is fermented in the colon, with a stoichiometry in vivo and in vitro indicating relatively little $\mathrm{H}_{2}$ gas production (Livesey et al. 1993).

Lactitol. Very little of this disaccharide polyol is absorbed, perhaps $2 \%$ as lactitol and its hydrolysis products galactose and sorbitol. This is due to a very low activity of 
$\beta$-galactosidase in the human intestine (Nilsson \& Jägerstad, 1987; Grimble et al. 1988). The liver readily uses absorbed galactose and sorbitol in either hepatic glycogen storage or hepatic glucose production. Unabsorbed lactitol is completely fermented with a stoichiometry giving a generous yield of $\mathrm{H}_{2}$ gas in vivo and in vitro (Livesey et al. 1993) and butyric acid in vitro (Clausen et al. 1998).

\section{Glycaemia and insulinaemia}

\section{Definitions}

Glycaemic index. GI is a measure of a specific property of carbohydrate in a food or meal or diet (Jenkins et al. 1981; Wolever et al. 1991; Food and Agriculture Organization, 1998). It is defined as 'the incremental area under the blood glucose response curve of a $50 \mathrm{~g}$ carbohydrate portion of a test food expressed as a percentage of the response to the same amount of carbohydrate from a standard food taken by the same subject' (Food and Agriculture Organization, 1998). In this definition carbohydrate usually means available carbohydrate, though has included for comparative purposes any carbohydrate that might replace available carbohydrate in a foodstuff (Pelletier et al. 1994; Bär, 2000; Zumbé et al. 2001; Foster-Powell et al. 2002; Sydney University's Glycaemic Index Research Service, 2002). The $50 \mathrm{~g}$ carbohydrate portion mentioned in the definition is not always practical and smaller portions (down to $25 \mathrm{~g}$ ) can be used when this is more realistic of the conditions of consumption. The standard food mentioned in the definition is usually glucose in water or white bread. To avoid confusion, it is useful to express the GI relative to glucose (for example, $\mathrm{G}=100 \mathrm{GI}$ units), and to state the standard food (being well defined, glucose is preferred) and its GI. Measurements are usually made on eight to ten adults consuming each test food on one occasion and the standard food ideally on three occasions. The calculation of GI has been standardised (Food and Agriculture Organization, 1998) and applied here with the following additional instructions: calculations were performed on group mean plasma glucose responses to carbohydrate ingestion; this minimises a bias caused by discounting below-baseline areas that occur due to random effects. Baseline values were taken at zero time rather than averaged across time before zero time; this minimises a bias due to the fall in basal glucose concentrations with time in the basal state. In studies reporting GI values these calculations were still necessary to ensure a standard and consistent approach was used.

GI values obtained in normal individuals usually apply to those with abnormal carbohydrate metabolism (Wolever $e t$ al. 1987; Foster-Powell et al. 2002); namely patients with type 1 diabetes mellitus (DM) (previously called juvenile or insulin-dependent $\mathrm{DM}$, which results from inadequate insulin secretion) and more commonly type $2 \mathrm{DM}$ patients (previously called adult or late onset diabetes, which is associated with the resistance of tissues to insulin). A provisional WHO classification of diabetes is available (Alberti
\& Zimmet, 1998), together with useful desktop guides on type 1 and 2 DM (European Diabetes Policy Group, $1999 a, b)$, and criteria for impaired glucose tolerance (GT) and impaired fasting glycaemia (Unwin et al.2002).

Glycaemic load. GL is formally the product of the carbohydrate content and GI of a food and so is primarily a measure of the quantity and apparent quality of the carbohydrate in the food item and has units of weight $(\mathrm{g})$. Foods with the same GL have practically the same impact on the integrated blood-glucose response, which in diabetes management is the main target.

Insulinaemic index. II is obtained under identical conditions to those for GI, simply replacing the measure of glucose with a measure of insulin. The index was introduced as a result of possible concern that blood-glucose responses might not adequately reflect the responses of the major anabolic hormone insulin, which is central to abnormal carbohydrate metabolism in DM (Holt et al. 1997; Wolever, 2000).

Insulin load. IL is calculated in the same way as GL, but replacing glucose measurements with insulin measurements.

Composite foods, meals and diets. The composite GL is the sum of GL from each food or ingredient item. Dividing this sum by the sum weight of the carbohydrate eaten gives the composite GI. Substitution of measures of glycaemia with measures of insulinaemia gives the composite insulin load and composite II.

Statistics. Studies from which GI and II values were calculated were generally of similar size and for simplicity were considered of equal weight when deriving overall means.

\section{Time course of acute glycaemic responses to polyols}

Glycaemic responses to sugars and polyols in fasted normal individuals of both sexes were summarised from the literature (Fig. 1). The curves are representative of $25 \mathrm{~g}$ doses taken in water or tea without milk or other nutrients $(80$ to $500 \mathrm{ml})$. The sugars (glucose and sucrose) result in higher responses 30-60 min after ingestion and lower glucose concentrations after 90 min than any of the polyols (erythritol, xylitol, sorbitol, mannitol, maltitol, isomalt, and lactitol). The responses to all polyols are lower or much lower than for sucrose. Glycaemic and insulinaemic responses (incremental areas) for sucrose and polyols, relative to equivalent intakes of glucose, were calculated for the studies represented in Fig. 1 and other studies. The responses were calculated using a wider range of intakes (10 to $70 \mathrm{~g}$ ), type 1 and type $2 \mathrm{DM}$ patients in addition to normal subjects, and maltitol syrups and polyglycitol in addition to the other polyols mentioned (Table 4). In the 

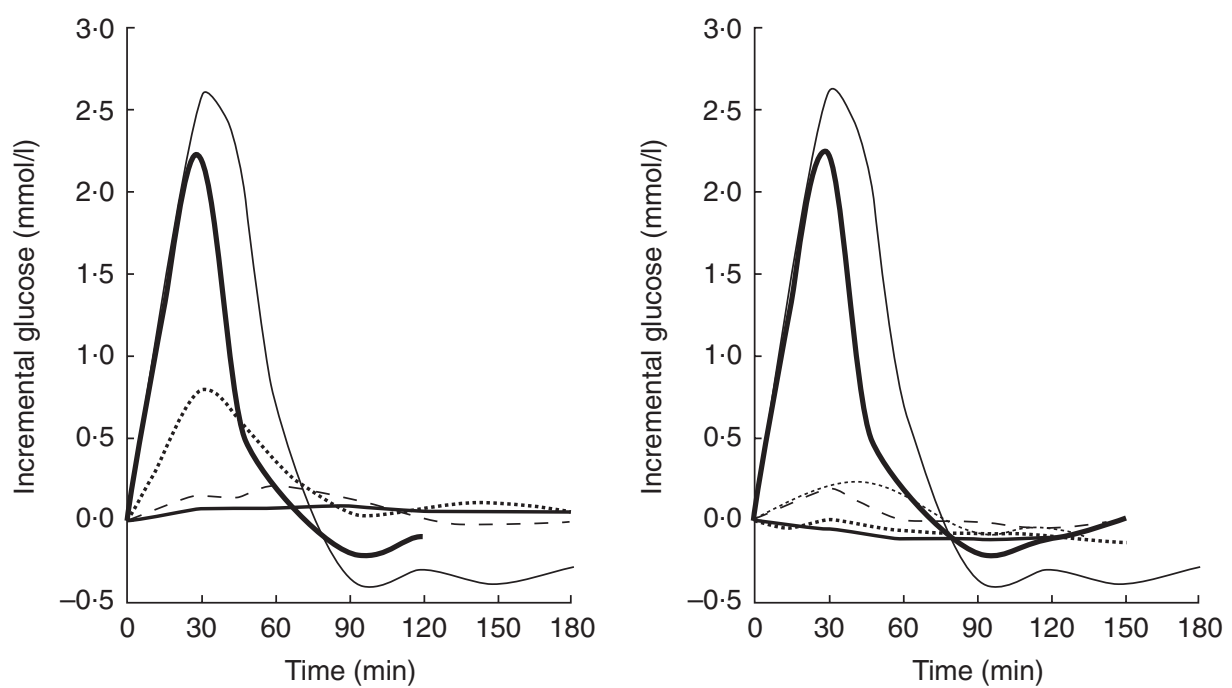

Fig. 1. (a), Glycaemic curves for glucose $(-)$, sucrose $(-)$ and polyols maltitol (....), isomalt $(---)$ and lactitol (-) in normal individuals; (b) glycaemic curves for glucose (-), sucrose (-) and polyols xylitol (.....), sorbitol $(---)$, erythritol (-.....) and mannitol $(-)$ in normal individuals. Data from several publications were pooled to yield curves representative of $25 \mathrm{~g}$ doses (20-64 g for erythritol) in water or tea (80 to $500 \mathrm{ml}$ ) without other nutrients. In practice, individual studies used various doses, and dose was used as a covariate at each time point to obtain curves representing $25 \mathrm{~g}$ intake. Based on data in Table 4 for normal subjects.

majority of publications such calculations had either not been undertaken or had been undertaken incorrectly due to the literature pre-dating knowledge of the current GI calculation method. In type $1 \mathrm{DM}$ patients supported by an artificial pancreas the rate of insulin delivery was in some cases used as a surrogate for insulinaemia.

Glucose and insulin measurements were invariably made on venous plasma or capillary blood. Glucose was the most common reference carbohydrate used. In a small number of cases sucrose was the reference carbohydrate, in which case responses were still expressed relative to glucose having 100 GI units. Statistical presentations (means, standard errors and differences) are omitted from Table 4 due to the possible heterogeneous nature of the data with respect to the level of polyol intake and the condition of subjects' carbohydrate metabolism, which are now examined.

\section{Glycaemic responses in normal, type 1 and type 2 diabetes mellitus subjects}

Information on glycaemic responses was available for sorbitol, isomalt and hydrogenated starch hydrolysates (intermediate- and high-maltitol syrups combined) in normal, type 1 and type $2 \mathrm{DM}$ subjects and for maltitol in normal and type $1 \mathrm{DM}$ subjects. Diabetics had $\mathrm{HbA}_{1 \mathrm{c}}$ values of less than $12 \%$ indicating a degree of glucose control, thought less than aimed for nowadays. For each polyol, glycaemic responses expressed relative to glucose in both types of diabetes were similar to those in normal subjects (Fig. 2).

\section{Relationship of glycaemic response to intake of polyols}

Information was available for sucrose, maltitol, high-maltitol syrup, isomalt, lactitol and sorbitol to assess the relationship between intake and glycaemic response relative to the most commonly used reference, glucose (Fig. 3). Sorbitol, isomalt and lactitol had very low to little responses at all intakes and there was no association with dose. Responses tended to fall either significantly or numerically with increasing dose for sucrose $(P<0.02)$, maltitol $(P=0 \cdot 06)$ and high-maltitol syrup $(P=0 \cdot 16)$. Such possible dose dependence is not limited to soluble carbohydrates as it is also observed for bread $v$. glucose (Jenkins $e t$ al. 1981; Wolever \& Bolognesi, 1996; Lee \& Wolever, 1998).

Sucrose is a carbohydrate often replaced by polyols in foodstuffs. When incremental glucose-response areas for polyols were re-expressed relative to a sucrose standard set at $65 \mathrm{GI}$ units at all intakes (Fig. 3 (b)), the relative glycaemic response to all polyols was clearly independent of dose.

\section{Glycaemic and insulinaemic indices of polyols}

The achievement of low postprandial glycaemia is an important goal and has greater significance when accompanied by low insulinaemia. All polyols had lower GI and II values than either glucose or sucrose (Table 5).

Among these carbohydrates GI and II were related practically linearly (Fig. 4) with a slope of association of 0.75 (SE 0.05) (dimensionless); this slope is significantly less than might be expected $(P<0 \cdot 0001)$; for glucose the value would by definition fall on a line passing through the origin of slope $1 \cdot 00$.

Variations about mean GI and II values possibly increased with increasing value; homogeneity was achieved by transformation to the square root (Fig. 4 (b)). Observations falling below the line of identity (Fig. 4 (a) and (b)) are consistent with causing demand on the pancreas for insulin that is lower than that due to glucose, and 
Table 4. Estimates of the relative glucose response $(R G R)$ and relative insulin response $(R I R)$ to sucrose and polyols $($ glucose $=100)$

\begin{tabular}{|c|c|c|c|c|c|c|c|}
\hline \multirow[b]{2}{*}{ Reference (RGR, RIR) ${ }^{*}$} & \multirow[b]{2}{*}{ Intake (g) } & \multirow[b]{2}{*}{ RGR } & \multirow[b]{2}{*}{ RIR } & \multirow[b]{2}{*}{ Subjects } & \multirow[b]{2}{*}{$n$} & Composition (\%) & \multirow[b]{2}{*}{ Source } \\
\hline & & & & & & $\mathrm{S} \mathrm{Ma} \mathrm{H}$ & \\
\hline \multicolumn{8}{|l|}{ Sucrose } \\
\hline Glucose $(100,100) \dagger$ & 20 & 89 & 33 & Normal & $9 \mathrm{M}$ & & MacDonald et al. (1978) \\
\hline Glucose $(100,-)$ & 20 & 87 & na & Normal & 12 & & Samata et al. (1985) \\
\hline Glucose $(100,-)$ & 20 & 89 & na & Type 2 DM & 8 & & Samata et al. (1985) \\
\hline Glucose $(100,-)$ & 20 & 79 & na & Type 1 DM & 6 & & Samata et al. (1985) \\
\hline Glucose $(100,100)$ & 25 & 58 & 58 & Normal & $4 \mathrm{M}+4 \mathrm{~F}$ & & Lee \& Wolever (1998) \\
\hline Glucose $(100,100)$ & 25 & 80 & 43 & Normal & $8 \mathrm{M}$ & & Pelletier et al. (1994) \\
\hline Glucose $(100,100) \dagger$ & 35 & 58 & 23 & Normal & $9 \mathrm{M}$ & & MacDonald et al. (1978) \\
\hline Glucose $(100,100)$ & 50 & 58 & 45 & Normal & $4 \mathrm{M}+4 \mathrm{~F}$ & & Lee \& Wolever (1998) \\
\hline Glucose $(100,100) \dagger$ & 50 & 64 & 43 & Normal & $9 \mathrm{M}$ & & MacDonald et al. (1978) \\
\hline Glucose $(100,-)$ & 50 & 65 & na & Normal & - & & Brand-Miller et al. (1999) \\
\hline Glucose $(100,100) \dagger$ & 70 & 75 & 45 & Normal & $9 \mathrm{M}$ & & MacDonald et al. (1978) \\
\hline Glucose $(100,100)$ & 100 & 58 & 67 & Normal & $4 \mathrm{M}+4 \mathrm{~F}$ & & Lee \& Wolever (1998) \\
\hline \multicolumn{8}{|l|}{ Erythritol } \\
\hline Glucose $(100,100)$ & 17 & 21 & 3 & Normal & $5 \mathrm{M}$ & & Noda et al. (1994) \\
\hline Glucose $(100,100) \ddagger$ & 64 & $0(-5)$ & 1 & Normal & $3 M+3 F$ & & Bornet et al. (1996a) \\
\hline Glucose $(100,100) \ddagger$ & 20 & $0(-20)$ & 3 & Type 2 DM & $3 M+8 F$ & & Ishikawa et al. (1996) \\
\hline Glucose $(100,-) \ddagger$ & 40 & 3 & - & Normal & 6 & & $\begin{array}{l}\text { PD Cock, Cerestar } \\
\text { (unpublished results) }\end{array}$ \\
\hline \multicolumn{8}{|l|}{ Xylitol } \\
\hline Glucose $(100,100)$ & 20 & 13 & 4 & Normal & $5 \mathrm{M}+5 \mathrm{~F}$ & & Nguyen et al. (1993) \\
\hline Glucose $(100,100)$ & 25 & 9 & 31 & Normal & $8 \mathrm{M}$ & & Natah et al. (1997) \\
\hline Glucose $(100,100)$ & 30 & 14 & 12 & Normal & $3 M+3 F$ & & Salminen et al. (1982) \\
\hline Glucose $(100,-)$ & 30 & 15 & na & Normal & $5 \mathrm{M}+5 \mathrm{~F}$ & & Müller-Hess et al. (1975) \\
\hline Glucose $(100,100)$ & 50 & 7 & 14 & Normal & 30 & & Tong et al. (1987) \\
\hline Glucose $(100,100)$ & 50 & 18 & 14 & Normal & $5 \mathrm{M}+5 \mathrm{~F}$ & & Müller-Hess et al. (1975) \\
\hline \multicolumn{8}{|l|}{ Mannitol } \\
\hline Glucose $(100,100)$ & 25 & 0 & 0 & Normal & 5 & & Ellis \& Krantz (1941) \\
\hline \multicolumn{8}{|l|}{ Sorbitol } \\
\hline Glucose $(100,100)$ & 20 & 13 & 4 & Normal & $8 \mathrm{M}$ & & Nguyen et al. (1993) \\
\hline Glucose $(100,100) \dagger$ & 20 & 7 & 36 & Normal & $9 \mathrm{M}$ & & MacDonald et al. (1978) \\
\hline Sucrose $(81,-)$ & 20 & 14 & 7 & Type 1 DM§ & $18 M+6 F$ & & Kaspar \& Spengler (1984) \\
\hline Glucose $(100,-)$ & 25 & 10 & na & Normal & 7 & & Ellis \& Krantz (1941) \\
\hline Glucose $(100,100) \dagger$ & 35 & 3 & 12 & Normal & $9 \mathrm{M}$ & & MacDonald et al. (1978) \\
\hline Sucrose $(68,40)$ & 4011 & 11 & 19 & Type 2 DM & $10 M+8 F$ & & Petzoldt et al. $(1982 b)$ \\
\hline Glucose $(100,-)$ & 50 & 14 & na & Normal & 2 & & Ellis \& Krantz (1941) \\
\hline Glucose $(100,100) \dagger$ & 50 & 6 & 15 & Normal & $9 \mathrm{M}$ & & MacDonald et al. (1978) \\
\hline Glucose $(100,100)$ & 50 & 8 & 6 & Normal & $9(M+F)$ & & Mimura et al. (1972) \\
\hline Glucose $(100,-)$ & 50 & 4 & na & Type 2 DM & 13 & & Ellis \& Krantz (1943) \\
\hline Maltitol & & & & & & & \\
\hline Glucose $(100,100)$ & 20 & 44 & 23 & Normal & $5 \mathrm{M}+5 \mathrm{~F}$ & $-98-$ & Nguyen et al. (1993) \\
\hline Glucose $(100,100)$ & 25 & 49 & 30 & Normal & $8 \mathrm{M}$ & $-99-$ & Pelletier et al. (1994) \\
\hline Glucose $(100,-)$ & 50 & 25 & na & Normal & $9(\mathrm{M}+\mathrm{F})$ & 98ๆ & Mimura et al. (1972) \\
\hline Glucose $(100,100)$ & 50 & 37 & 21 & Type 2 DM & $11(\mathrm{M}+\mathrm{F})$ & $98 \emptyset$ & Mimura et al. (1972) \\
\hline Glucose $(100,100)$ & 50 & 39 & 29 & Normal & $12 \mathrm{M}$ & $-99-$ & Kamoi (1974) \\
\hline Glucose $(100,-)$ & 50 & 31 & na & Normal & $14 M+5 F$ & - $99-$ & Kamoi (1974) \\
\hline Glucose $(100,-)$ & 50 & 39 & na & 'Diabetic' & $14 \mathrm{M}+7 \mathrm{~F}$ & $-99-$ & Kamoi (1974) \\
\hline Glucose $(100,100)$ & 50 & 25 & 27 & Type 2 DM & 6 & $-98-$ & Slama (1989) \\
\hline Glucose $(100,100)$ & 50 & 29 & 33 & Normal & 6 & $-98-$ & Slama (1989) \\
\hline Maltitol syrups & & & & & & & \\
\hline High-maltitol syrup (abou & $89 \%$ maltit & & & & & & \\
\hline Glucose $(100,100) \ddagger$ & 10 & 65 & na & Normal & 6 & $-89-$ & Secchi et al. (1986) \\
\hline Glucose $(100,100) \ddagger$ & 25 & 48 & na & Normal & 6 & $-89-$ & Secchi et al. (1986) \\
\hline Glucose $(100,100)$ & 25 & 37 & 48 & Normal & $8 \mathrm{M}$ & $\begin{array}{lll}588 & 7\end{array}$ & Pelletier et al. (1994) \\
\hline Sucrose $(71,34)$ & 30 & 55 & 28 & Normal & 8 & 28810 & Felber et al. (1987) \\
\hline Glucose $(100,100)$ & 35 & 47 & 28 & Normal & $8 M+8 F$ & 5896 & Kearsley et al. (1982) \\
\hline Glucose $(100,100)$ & 50 & 33 & 36 & Normal & 6 & $-89-$ & Secchi et al. (1986) \\
\hline Glucose $(100,100) \ddagger$ & 50 & 50 & na & Normal & 6 & $-89-$ & Secchi et al. (1986) \\
\hline Intermediate-maltitol syru & (about 70 & $\%$ maltit & & & & & \\
\hline Glucose $(100,100)$ & 25 & 54 & 29 & Normal & $8 \mathrm{M}$ & 27226 & Pelletier et al. (1994) \\
\hline Glucose $(100,100)$ & 50 & 52 & 27 & Normal & $3 M+3 F$ & 76933 & Wheeler et al. (1990) \\
\hline Glucose $(100,100)$ & 50 & 52 & na & Type 1 DM & $3 M+3 F$ & 86933 & Wheeler et al. (1990) \\
\hline Glucose $(100,100)$ & 50 & 56 & 66 & Type 2 DM & $3 M+3 F$ & 96933 & Wheeler et al. (1990) \\
\hline
\end{tabular}


Table 4. Continued

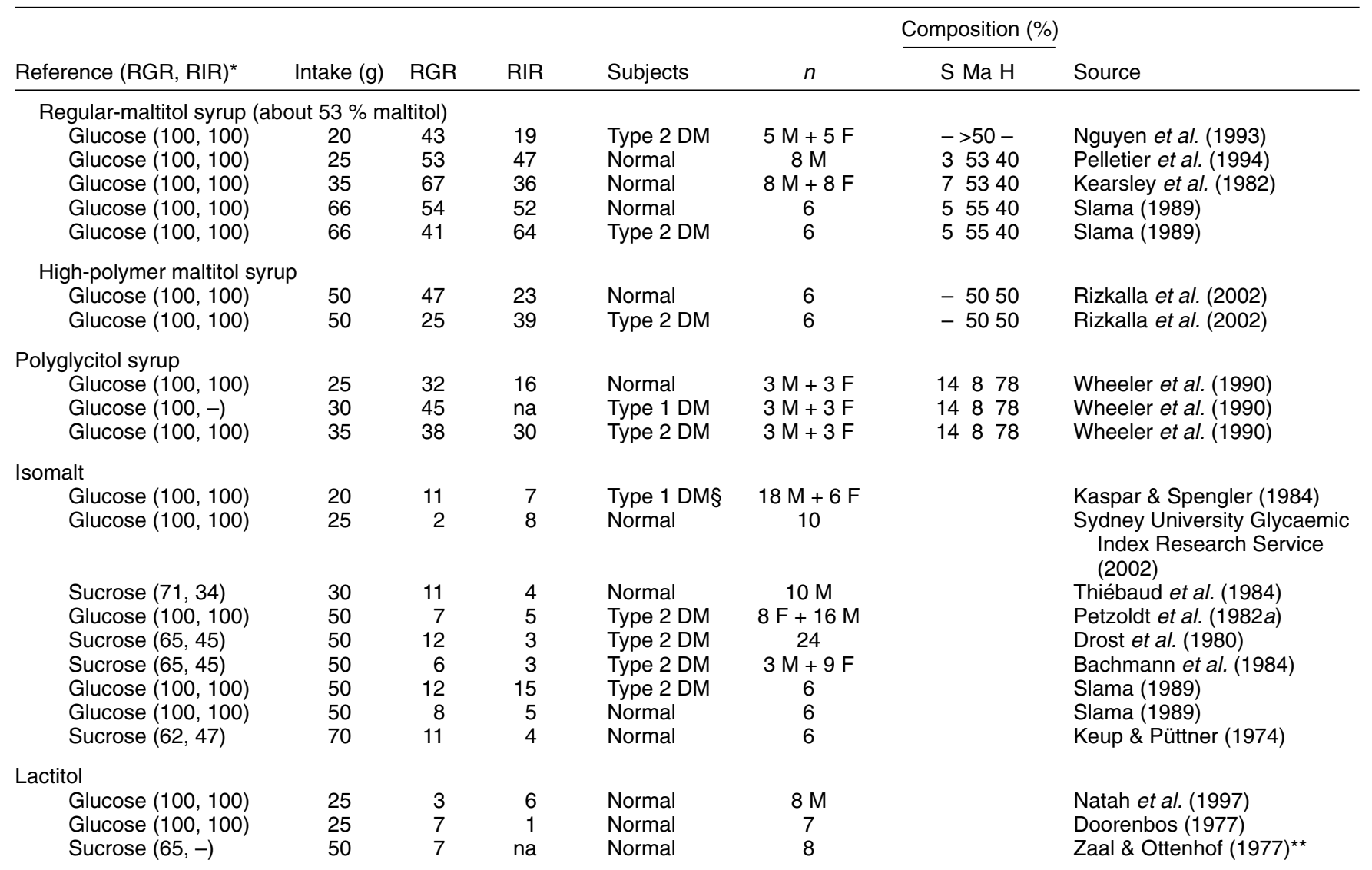

$\mathrm{S}$, sorbitol; Ma, maltitol; $\mathrm{H}$, hydrogenated saccharides with degree of polymerisation > 2; M, male; na, information not available; DM, diabetes mellitus; $\mathrm{F}$, female.

*Values of RGR and RIR at the intakes of reference substrate used are shown in parentheses. These data are used to adjust to a glucose reference of 100 when the reference substrate in the study was other than glucose.

† Unpaired reference: data were adjusted for glucose responsiveness according to the treatment group's fasting glucose concentrations

† Unpaired reference: data taken from a separate publication with adjustment for fasting glucose concentration. RGR data in parentheses are acutal, outside parentheses are conventional.

$\S$ Subjects with artificial pancreas.

II Intake was 4 x $10 \mathrm{~g}$ doses at hourly intervals over $240 \mathrm{~min}$.

ๆ $98 \%$ assumed based on production by hydrogenation of maltose.

** Partially reported by van Velthuijsen (1990).

more than simply due to the GI of polyols and sucrose being lower than for glucose.

\section{Composite glycaemic index, glycaemic load, insulinaemic index and insulin load: potential interactions}

Interactions between polyols and sugar, and between polyols and foods. Seven studies involving polyols provided the possibility to assess whether the sum of the GL for meal components fed separately from one another would equal the GL of the entire meal (Table 6).

A meal composed of glucose and sorbitol (monosaccharide mixture) yielded a GL less than predicted from the sum of the loads for glucose and sorbitol separately (Table 6; cases 1 and 2). Incomplete hydrolysis cannot explain this result; possibly sorbitol slows stomach emptying or hurries the glucose to a site where absorption distally is less rapid (Livesey et al. 1998) or signifi- cantly dilutes luminal glucose concentration through its osmotic effect. A similar observation is made for a meal of a disaccharide mixture, sucrose and lactitol (Table 6; case 3 ). Likewise a similar result is observed for sorbitol taken in comparatively complex meals; a breakfast comprising mainly bread and butter (Table 6; cases 4 and 5) and a protein-and-carbohydrate-based breakfast, mainly scrambled eggs and farina cereal (1088 kJ (260 kcal); Akgün \& Ertel, 1980) to which was added either sucrose or fructose or sorbitol (35 g) (Table 6; case 6). The last study was repeated in type 2 DM patients with similar results (Table 6; case 7).

Similar results were obtained when GI and load were replaced by II and load (Table 7), suggesting that the interaction affecting glycaemia was not the result of interaction to elevated insulin secretion.

The general case is evidently that a mixture involving a polyol yields a value less than the sum of its individual 


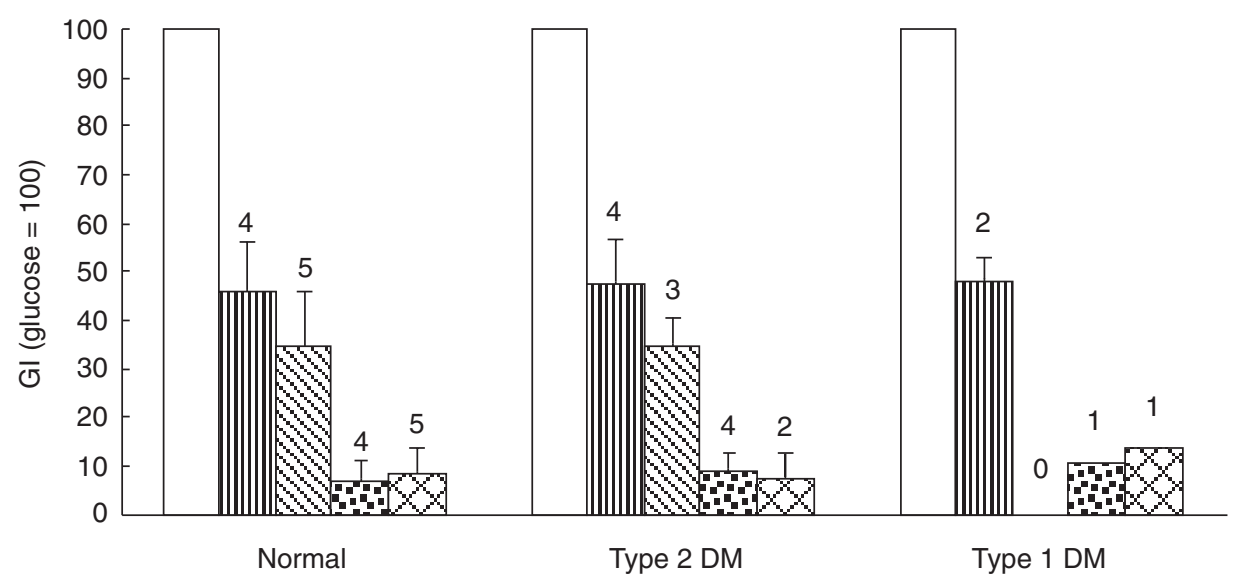

Fig. 2. The glycaemic response for four polyols relative to glucose ( $\square$ ) in normal, type 2 diabetes mellitus (DM) and type 1 DM subjects. Values are the means of the responses for individual studies shown in Table 4, which cites the sources of information for the calculations made. The numbers of studies represented are shown above each column and the vertical bars represent either standard deviation ( $n \geq 3$ studies) or range $(n 2)$ or are absent $(n 1)$. Hydrogenated starch hydrolysate (西) is equally weighted information combined from polyglycitol and regular maltitol syrup. (囦), Maltitol; (団), isomalt; (囚), sorbitol.

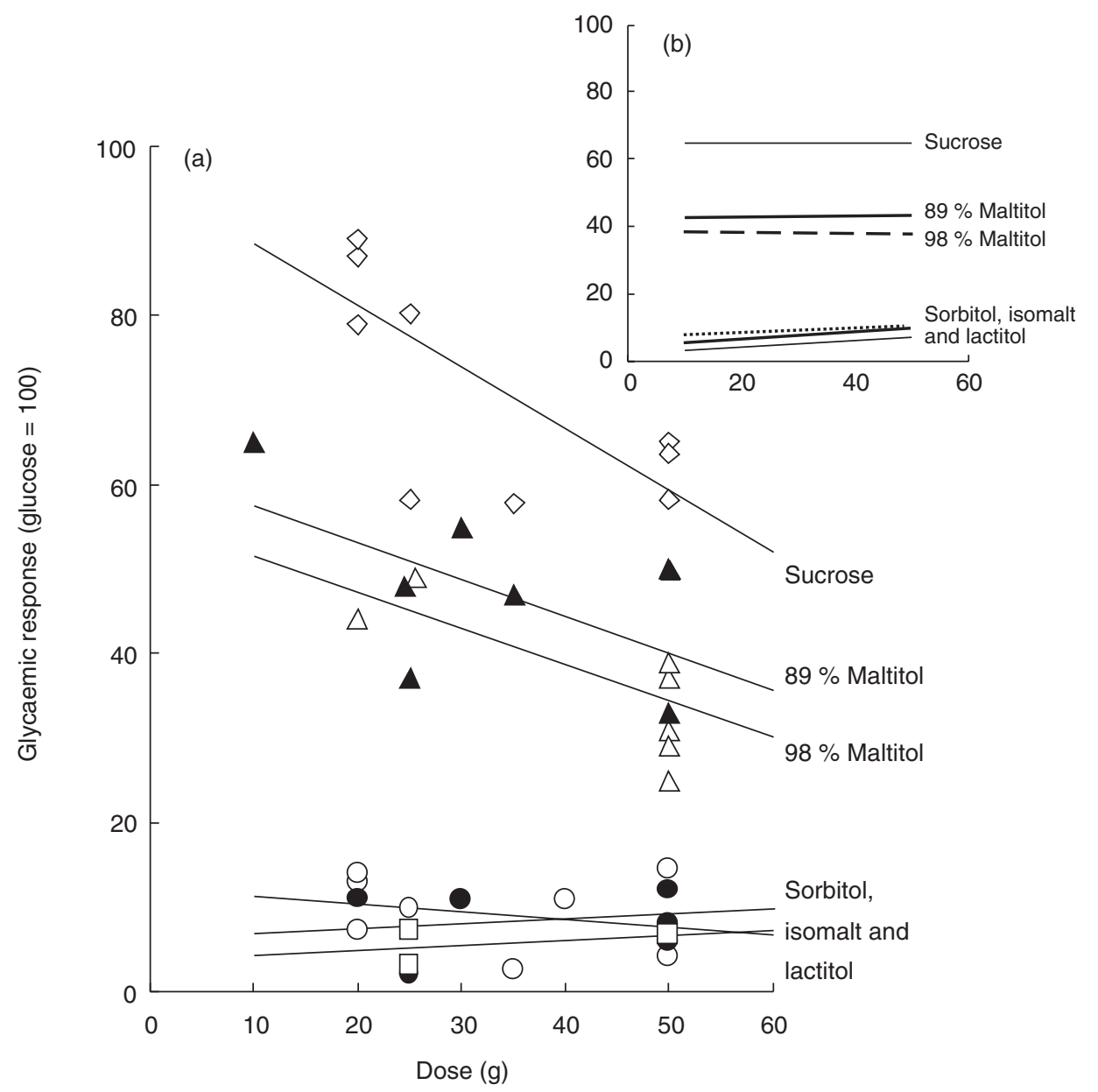

Fig. 3. Glycaemic response area for sucrose and polyols relative to glucose (glycaemic index (GI) = 100) (a) or sucrose (GI =65) (b). Carbohydrates were taken in water or tea without other nutrients (80 to $500 \mathrm{ml})$. Data are inclusive of normal, type 2 diabetes mellitus (DM) and type 1 DM subjects and are from Table 4, which cites the sources of information used in the calculations. ( $\diamond)$, Sucrose; $(\boldsymbol{\Delta})$, high-maltitol syrup; $(\triangle)$, maltitol; $(\bigcirc)$, sorbitol; $(\bullet)$, isomalt; $(\square)$, lactitol. Regression curves for glucose $=100$ at each intake were:

Sucrose relative glucose response $(\mathrm{RGR})=95(\mathrm{SE} 8)+$ intake $\times(-0.70($ SE 0.24)),$P=0.02$; High-maltitol syrup RGR $=62(\mathrm{SE} 9)+$ intake $\times$ $(-0.43$ (SE 0.27)), $P=0.16$; Maltitol RGR $=56($ SE 10) + intake $\times(-0.42($ SE 0.23$)), P=0.10$; Sorbitol RGR $=12($ SE 4$)+$ intake $\times(-0.09($ SE $0.10)), P=0.39$; Isomalt RGR $=6$ (SE 4$)+$ intake $\times(0.06($ SE 0.06$)), P=0.53$; Lactitol RGR $=3($ SE 5$)+$ intake $\times(0.07($ SE 0.14$)), P=0.72$. 
Table 5. Glycaemic and insulinaemic indices of polyols*

\begin{tabular}{|c|c|c|c|c|c|c|}
\hline \multirow[b]{2}{*}{ Polyol } & \multicolumn{3}{|c|}{$\begin{array}{l}\text { Glycaemic index } \\
\text { (glucose = 100) }\end{array}$} & \multicolumn{3}{|c|}{$\begin{array}{l}\text { Insulinaemic index } \\
\quad(\text { glucose }=100)\end{array}$} \\
\hline & Mean & SD & $n \dagger$ & Mean & SD & $n \dagger$ \\
\hline Erythritol & 0 & 17 & 4 & 2 & 1 & 3 \\
\hline Xylitol & 13 & 4 & 6 & 11 & 5 & 4 \\
\hline Sorbitol & 9 & 4 & 10 & 11 & 6 & 6 \\
\hline Mannitol & 0 & - & 1 & 0 & - & 1 \\
\hline Isomalt & 9 & 3 & 9 & 6 & 4 & 9 \\
\hline Lactitol & 6 & 2 & 3 & 4 & $3 \ddagger$ & 2 \\
\hline Maltitol & 35 & 9 & 9 & 27 & 5 & 6 \\
\hline \multicolumn{7}{|l|}{ Maltitol syrups } \\
\hline High-maltitol syrup & 48 & 11 & 7 & 35 & 10 & 4 \\
\hline Intermediate-maltitol syrup & 53 & 2 & 4 & 41 & 22 & 3 \\
\hline Regular-maltitol syrup & 52 & 10 & 5 & 44 & 17 & 5 \\
\hline High-polymer maltitol syrup & 36 & $11 \ddagger$ & 2 & 31 & $8 \ddagger$ & 2 \\
\hline Polyglycitol & 39 & 7 & 3 & 23 & $7 \ddagger$ & 2 \\
\hline
\end{tabular}

* Data are the means of study values for relative glucose responses and relative insulin responses in Table 4 , ignoring intake as a cause of variance when glucose is the reference carbohydrate. Observations obtained with $>50 \mathrm{~g}$ intake were excluded from the analysis. For the insulinaemic index, one observation on xylitol and one observation on sorbitol were excluded as outliers from the analysis due to their being $>6$ standardised residuals from the results shown.

$\dagger$ No. of studies.

$\ddagger$ Plus and minus half range of the two values.

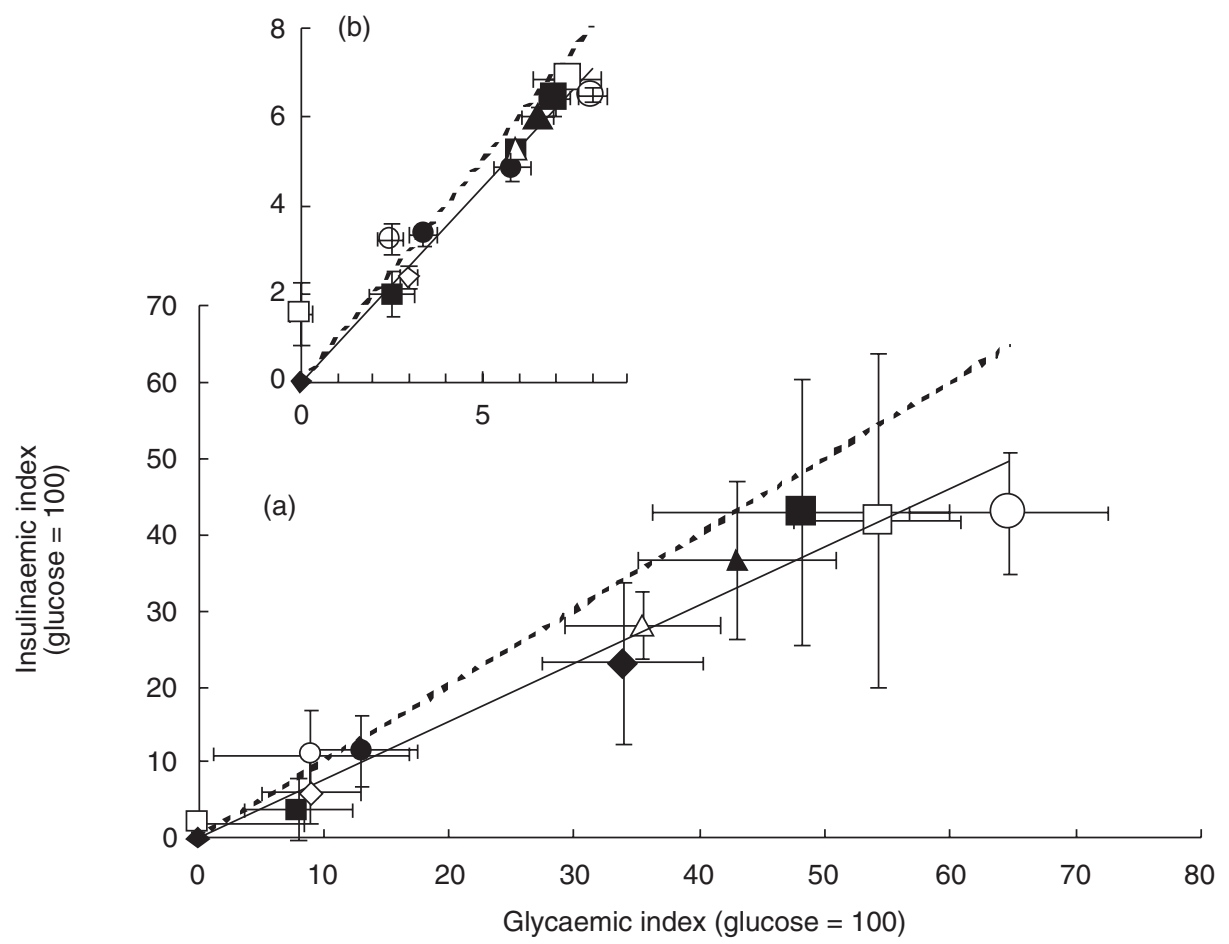

Fig. 4. Relationship (-; Slope $=0.75$ (SE 0.05)) of the insulinaemic index to the glycaemic index for polyols and sucrose for untransformed data (a) and square root transformations (b). Data are from Table 5 and are means, with standard errors represented by vertical and horizontal

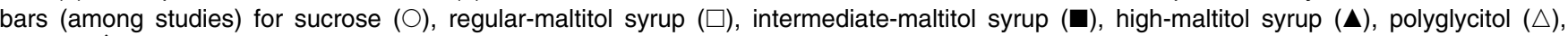
maltitol $(\diamond)$, sorbitol $(\bigcirc)$, xylitol $(\bullet)$, isomalt $(\diamond)$, lactitol $(\mathbf{\square})$, erythritol $(\square)$, and mannitol $(\bullet)$. (- - -), Unity.

parts. A single instance departed from the general case and occurred in type 2 DM patients (Table 7; case 7). Here the interaction is as expected for the GL, but not for the insulinaemic load, and this could be due to a marked impairment of insulin secretion in the patients studied.
In conclusion, the GI and II and loads of the polyols apply approximately in the context of simple meals of sugars (glucose, sucrose), starches (bread) and protein (scrambled egg and farina cereal) and without overestimation (Tables 6 and 7). A similar conclusion was drawn for 
Table 6. Interaction between polyols and other dietary components affecting glycaemic index*

\begin{tabular}{|c|c|c|c|c|}
\hline & \multirow[b]{2}{*}{ Intake $(g)$} & \multicolumn{3}{|c|}{ Glycaemic } \\
\hline & & Index & & Loadl† (g) \\
\hline \multicolumn{5}{|c|}{ Case 1: normal subjects, $n 16,8 \mathrm{M}+8 \mathrm{~F}$ (Kearsley et al. 1982) } \\
\hline Sorbitol & $17 \cdot 5$ & 10 & & 1.75 \\
\hline Glucose & $17 \cdot 5$ & 100 & & $17 \cdot 5$ \\
\hline Predicted sum for mixture & & & & $19 \cdot 25$ \\
\hline Observed for mixture & & & & $15 \cdot 05$ \\
\hline Observed/predicted value & & & & $0 \cdot 78$ \\
\hline \multicolumn{5}{|c|}{ Case 2: normal subjects, $n 16,8 \mathrm{M}+8 \mathrm{~F}$ (Kearsley et al. 1982) } \\
\hline Sorbitol & $15 \cdot 1$ & 10 & & 1.51 \\
\hline Glucose & $20 \cdot 0$ & 100 & & 19.95 \\
\hline Predicted sum for mixture & & & & $21 \cdot 46$ \\
\hline Observed for mixture & & & & $17 \cdot 50$ \\
\hline Observed/predicted value & & & & 0.82 \\
\hline \multicolumn{5}{|c|}{ Case 3: normal subjects, $n 8$ (Zaal \& Ottenhof,1977) } \\
\hline Lactitol & 50 & 6 & & 3 \\
\hline Sucrose & 50 & 65 & & $32 \cdot 5$ \\
\hline Predicted sum for mixture & & & & $35 \cdot 5$ \\
\hline Observed for mixture & & & & $25 \cdot 8$ \\
\hline Observed/predicted value & & & & 0.73 \\
\hline \multicolumn{5}{|c|}{ Case 4: type 2 DM, $n 12$ (Drost et al. 1985) } \\
\hline Bread (and butter) & 36 & 70 & & $25 \cdot 2$ \\
\hline Sorbitol & 22 & 10 & & $2 \cdot 2$ \\
\hline Predicted sum for mixture & & & & $27 \cdot 4$ \\
\hline Observed for mixture & & & & $16 \cdot 7$ \\
\hline Observed/predicted value & & & & 0.61 \\
\hline \multicolumn{5}{|c|}{ Case 5: type $1 \mathrm{DM} \neq, n$ 9, $3 \mathrm{M}+6 \mathrm{~F}$ (Vaaler et al. 1987) } \\
\hline Bread (and butter) & 75 & 70 & & $52 \cdot 5$ \\
\hline Sorbitol & 21 & 10 & & $2 \cdot 1$ \\
\hline Predicted sum for mixture & & & & $54 \cdot 6$ \\
\hline Observed for mixture & & & & $49 \cdot 8$ \\
\hline Observed/predicted value & & & & 0.91 \\
\hline \multicolumn{5}{|c|}{ Cases 6 and 7: normal, $n$ 10; type $2 \mathrm{DM}, n 6$ respectively (Akgün \& Ertel, 1980) } \\
\hline Protein and carb meal + sucrose & & $\S$ & $56 \cdot 1$ & $37 \cdot 0$ \\
\hline Protein and carb meal + fructose & & $\S$ & $41 \cdot 4$ & $22 \cdot 3$ \\
\hline 'Protein and carb meal' predicted & & $\S$ & $33 \cdot 4$ & $14 \cdot 3$ \\
\hline Sorbitol & 35 & 10 & 3.5 & 3.5 \\
\hline Predicted sum for mixture & & & $36 \cdot 9$ & $17 \cdot 8$ \\
\hline Observed for mixture & & & $11 \cdot 6$ & $15 \cdot 4$ \\
\hline Observed/predicted value & & & 0.31 & 0.87 \\
\hline
\end{tabular}

$\mathrm{M}$, male; F, female; DM, diabetes mellitus; carb, carbohydrate; GI, glycaemic index.

* Gl values are from Table 5 or calculated references cited.

† Glycaemic load $=$ intake $\times \mathrm{Gl} / 100$.

‡ Supported with continuous subcutaneous insulin infusion

$\S$ Glycaemic loads calculated assuming the difference in glycaemic response between the sucrose and fructose meal was equal to the difference in glycaemic loads from sucrose $(35 \mathrm{~g} \times \mathrm{Gl} 65 / 100)$ and fructose $(35 \mathrm{~g} \times \mathrm{Gl} 23 / 100)$.

individual foods in the context of foods and more complex mixed meals (Collier et al. 1986; Wolever \& Jenkins, 1986; Bornet et al. 1987). In both circumstances the composite GI (and GL) and II (and IL) were slightly less than predicted from the GI and II of individual components or foods. Importantly, the present results indicate that the potential benefits of low GI and II would not be diminished due to the co-ingestion of very low-GI polyols with protein and available carbohydrate in a meal context.

Interaction between polyols and fat. Chocolate is a source of both carbohydrate and fat. The glycaemic response to sucrose (GI 65 (SD 9)) is lower when in chocolate (GI 30 (SD 9)) (values recalculated from Pelletier et al. 1994).
Similarly, the glycaemic response to maltitol (GI 35 (SD 7)) may be lower in chocolate (GI 29 (SD 7)) (Pelletier et al. 1994). These responses may be attributed to slower stomach emptying, but also to a higher insulin response in the presence of fat. Indeed, interactions between carbohydrate and fat are known to elevate insulinaemia and reduce glycaemia (Collier et al. 1988; Morgan et al. 1988). Thus, the II of sucrose (43 (SD 14)) is higher when in chocolate (76 (SD 24)); likewise the II of maltitol (27 (SD 10)) $v$. maltitol in chocolate (82 (SD 25)) (Pelletier et al. 1994). With other polyols (isomalt, erythritol) no such interactions were evident when comparing the present results for pure polyols (Table 5) with those from elsewhere for polyols eaten with fat, in chocolate (Gee et al. 1991; Bornet et al. 1996b). 
Table 7. Interaction between polyols and other components affecting insulinaemic index*

\begin{tabular}{|c|c|c|c|c|}
\hline & Intake $(\mathrm{g})$ & \multicolumn{3}{|c|}{ Insulinaemic } \\
\hline Case 3: no insulin data & & & & \\
\hline Case 5: no insulin data & & & & \\
\hline $\begin{array}{l}\text { Cases } 6 \text { and } 7: \text { normal, } n 10 \text {; type } 2 \\
\text { Protein and carb meal + sucrose } \\
\text { Protein and carb meal + fructose } \\
\text { 'Protein and carb meal' predicted } \\
\text { Sorbitol } \\
\text { Predicted sum for mixture } \\
\text { Observed for mixture } \\
\text { Observed/predicted value }\end{array}$ & 35 & $\begin{array}{r}\ddagger \\
\ddagger \\
\ddagger \\
11\end{array}$ & $\begin{array}{r}33 \cdot 4 \\
23 \cdot 6 \\
18 \cdot 4 \\
3 \cdot 9 \\
22 \cdot 2 \\
10 \cdot 0 \\
0.45\end{array}$ & $\begin{array}{r}64 \cdot 8 \\
55 \cdot 0 \\
49 \cdot 8 \\
3.9 \\
53 \cdot 6 \\
57 \cdot 5 \\
1.07\end{array}$ \\
\hline
\end{tabular}

Importantly, the potential benefit of a low glycaemic response per se to polyols is not lost when co-ingested with fat. The data would suggest, however, that to achieve low insulin responses in products that can be made only with appreciable amounts of fats then carbohydrate of particularly low glycaemic response would be needed. In view of a current understanding that high insulinogenic foods and diets may be adverse for health reasons it may be just as important (or possibly more important) to reduce the GI of carbohydrate in high-fat foods as it is to lower the amount of fat in the foods.

\section{Polyol-based snack foods}

Healthy individuals and individuals with disorders of carbohydrate metabolism alike can desire the sweet taste of foods requiring bulk sweeteners; sugars and polyols (Mehnert, 1971). A number of snack foods (which may also be eaten at mealtimes), sugars and polyols are listed in Table 8 , ranked by II. The carbohydrate content of a reasoned portion, as used in these studies, is also shown and is about $25 \mathrm{~g}$, much of which might be replaceable with polyols in manufactured goods.

Polyols rank very low on the II scale; however, this is not the case for all polyol products, thus (as discussed earlier; pp. 174-175) maltitol-based chocolate has an II comparable with sucrose-based chocolate, and much above the II for isomalt- and erythritol-based chocolate products. The latter two polyol products have II and GI values less than some fruits (oranges, apples, banana, grapes) and yoghurt. Both fruits and polyol products have II values that are less than for many other products. Some polyols may therefore be used to generate snack foods lower in II and GI than regular snack foods.

The lowering of insulinaemia between meals is well demonstrated for a polyol-based product by Bornet et al. (1996b). They fed sucrose- and erythritol-based chocolate between breakfast and lunch to type 2 DM patients, showing considerable savings on the demand for insulin (Fig. 5). Such responses are not limited to snacks since they are also observed after mixed meals as noted later (pp. 176-178). Thus also Hassinger et al. (1981) established that in diabetics requiring insulin, $30 \mathrm{~g}$ xylitol behaves as a low- 
Table 8. Snack meals, foods, sugars and polyols ranked by insulinaemic index (II)

\begin{tabular}{|c|c|c|c|c|c|c|}
\hline \multicolumn{2}{|c|}{ Meal item } & \multirow{2}{*}{$\frac{\text { Carbohydrate intake }(\mathrm{g})}{25}$} & \multirow{2}{*}{$\frac{\text { II }}{127}$} & \multirow{2}{*}{$\begin{array}{l}\text { GI } \\
26\end{array}$} & \multirow{2}{*}{$\frac{|I-G|}{101}$} & \multirow{2}{*}{$\frac{\text { Reference }}{*}$} \\
\hline 1 & Cereal and milk & & & & & \\
\hline 2 & Chocolate confection & 31 & 102 & 58 & 44 & $\dagger$ \\
\hline 3 & Glucose & - & 100 & 100 & 0 & \\
\hline 4 & White bread & - & 92 & 74 & 18 & $\ddagger$ \\
\hline 5 & Cheese, bread and milk & 25 & 89 & 8 & 81 & * \\
\hline 6 & Peanut butter, bread and milk & 25 & 88 & 14 & 73 & * \\
\hline 7 & Chocolate milk (drink) & 25 & 81 & 24 & 57 & * \\
\hline 8 & Ice cream & 26 & 79 & 52 & 27 & $t$ \\
\hline 9 & Milk chocolate (bar) & 25 & 79 & 25 & 54 & * \\
\hline 10 & Milk chocolate (bar) & 26 & 78 & 23 & 56 & * \\
\hline 11 & Maltitol chocolate & 25 & 82 & 30 & 52 & $\S$ \\
\hline 12 & Sucrose-based chocolate & 25 & 76 & 30 & 46 & $\S$ \\
\hline 13 & Banana & 32 & 68 & 58 & 10 & t \\
\hline 14 & Grapes & 15 & 68 & 54 & 14 & $t$ \\
\hline 15 & Yoghurt & 25 & 63 & 35 & 28 & * \\
\hline 16 & Fried chipped potato & $36 \cdot 5$ & 51 & 38 & 13 & * \\
\hline 17 & Peanut butter cup & 25 & 51 & 10 & 41 & * \\
\hline 18 & Oranges & $50 \cdot 6$ & 50 & 30 & 20 & $\dagger$ \\
\hline 19 & Potato chips (crisps) & 25 & 49 & 23 & 26 & * \\
\hline 20 & Apples & 18 & 49 & 38 & 11 & $\dagger$ \\
\hline 21 & Popcorn & $27 \cdot 4$ & 45 & 45 & 0 & $t$ \\
\hline 22 & Maltitol syrup (regular) & - & 44 & 52 & -8 & $\|$ \\
\hline 23 & Sucrose & - & 43 & 65 & -22 & $\|$ \\
\hline 24 & Maltitol syrup (high-polymer) & - & 31 & 36 & -5 & ॥ \\
\hline 25 & Maltitol & - & 27 & 35 & -8 & ॥ \\
\hline 26 & Polyglycitol & - & 23 & 39 & -16 & $\|$ \\
\hline 27 & Peanuts & $5 \cdot 4$ & 17 & 9 & 8 & $\dagger$ \\
\hline 28 & Isomalt chocolate & 31 & 16 & 13 & 3 & $\S$ \\
\hline 29 & Fructose & - & 15 & 23 & -8 & $\|$ \\
\hline 30 & Sorbitol & - & 11 & 9 & 2 & ॥ \\
\hline 31 & Xylitol & - & 11 & 13 & -2 & ॥ \\
\hline 32 & Isomalt & - & 6 & 9 & -3 & $\|$ \\
\hline 33 & Lactitol & - & 4 & 6 & -2 & ॥ \\
\hline 34 & Erythritol & - & 2 & 0 & 2 & ॥ \\
\hline 35 & Erythritol chocolate & 37 & 2 & - & - & $\S$ \\
\hline 36 & Mannitol & - & 0 & 0 & 0 & II \\
\hline
\end{tabular}

GI, glycaemic index; II, insulinaemic index.

* Computed from Shively et al. (1986).

† Computed from Holt et al. (1997).

‡ Computed from Jenkins et al. (1981), Wolever \& Bolognesi (1996a), and Lee \& Wolever (1998).

$\S$ Computed from Pelletier et al. (1994), Gee et al. (1991), and Bornet et al. (1996a).

II See Table 5.

glycaemic carbohydrate in the context of a high-protein mixed meal, reducing plasma glucose and insulin requirements by $50 \%$ compared with sucrose.

\section{Glycaemic control in groups of normal, type 1 and type 2 diabetes mellitus subjects}

Markers of glycaemic control include fasting plasma glucose (FPG), glucose tolerance (GT) or $2 \mathrm{~h}$ post GT during a $75 \mathrm{~g}$ oral GT test, $\mathrm{HbA}_{1 \mathrm{c}}$ (glycosylated or glycated) concentrations and appearance of urinary glucose, all of which fall with improvement in glycaemic control (Alberti \& Zimmet, 1998; Bastyr et al. 2000; Wang et al. 2002). The glucose response after a mixed meal (or meal GT) also provides an analogous measure to GT or $2 \mathrm{~h}$ post GT during a $75 \mathrm{~g}$ oral GT test. It is a relevant measure in longitudinal nutritional studies, though $\mathrm{HbA}_{1 \mathrm{c}}$ (and fructosamine as another marker of protein glycation) is probably the most relevant overall marker of glycaemic control and is now commonly used for this purpose. It is well established that both $\mathrm{HbA}_{1 \mathrm{c}}$ and fructosamine concentrations are reduced in diabetics by the consumption of low-glycaemic-carbohydrate diets (Jenkins et al. 2002), possibly more so when taken at each meal of the day.

When taken orally with meals at a readily tolerated dose, polyols may help to improve long-term glycaemic control in type $2 \mathrm{DM}$ patients, as expected for low-glycaemic carbohydrates. Thus polyols have provided an example of how a low-glycaemic carbohydrate can benefit type $2 \mathrm{DM}$ patients. A 12-week randomised controlled study of the impact of $6 \mathrm{~g}$ isomalt per meal ( $24 \mathrm{~g}$ daily) was undertaken on twenty-four subjects (twelve control and twelve parallel receiving isomalt). Measurements were made (Pometta $e t$ al. 1985) of $\mathrm{HbA}_{1 \mathrm{c}}$ (glycosylated) and FPG. In addition, the change in mealtime glycaemia was calculated by taking pre-treatment FPG as the baseline (change in this result then reflects the overall improvement due to the sum of chronic changes in FPG, meal GT and GI due to carbohydrate replacement).

The following data were subsequently ascertained by the present author's analysis. For the control group (no drugs, regular diet treatment alone) the underlying trend was for 


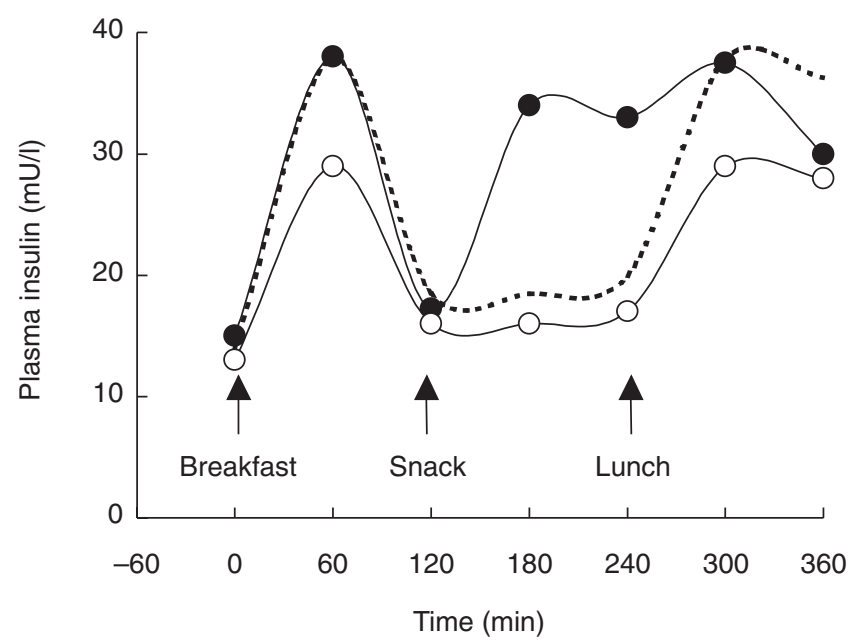

Fig. 5. Insulin demand between meals is reduced using a polyolbased snack food (Bornet et al. 1996b). (•), Sucrose-based chocolate snack between meals; $(\bigcirc)$, erythritol-based chocolate snack between meals. (---), Erythritol treatment group after adjustment upwards to account for differences in treatment-group mean responses to the breakfast $(1.48 \times$ area above the basal insulin concentration after breakfast).

glycaemic control to become progressively worse, though only slightly at an average rate of rise of $\mathrm{HbA}_{1 \mathrm{c}}$ of 0.022 (SE 0.006$) \%$ of the basal value per week $(P=0.035)$. This compares favourably with a worsening of twice this rate at approximately $0.05 \%$ of the basal value per week calculated for conventionally controlled type $2 \mathrm{DM}$ patients in other studies (UK Prospective Diabetes Study Group, 1998; Wallace \& Matthews, 2000). The isomalt treatment group by contrast maintained or improved $\mathrm{HbA}_{1 \mathrm{c}}$ concentrations. The differences in the mean of treatment outcomes in the present study were expressed as a percentage of the average of means (Fig. 6), an appropriate statistical method for results comparisons (Altman, 1991). Mealtime glycaemia was immediately lower due to treatment with isomalt, by 12.5 ( $\mathrm{SE} 2 \cdot 7) \%$, a difference that tended to widen with time to $20 \%$ lower after 3 months (Fig. 6) due to the combined improvement in FPG and meal GT. Relative to the control, the FPG fell at a significant rate of 0.5 (SE 0.1) \% per week, while the corresponding fall for $\mathrm{HbA}_{1 \mathrm{c}}$ was at a significant rate of $0.4(\mathrm{SE} 0.02) \%$ per week. The relative falls in FPG and $\mathrm{HbA}_{1 \mathrm{c}}$ were progressive with time and appeared not to have reached completion. These data contribute to the weight of data (Jenkins et al. 2002) showing that low-glycaemic carbohydrate ingestion by type $2 \mathrm{DM}$ patients can improve blood glucose control.

Other long-term studies on the effects of polyols in normal individuals and diabetic patients have been undertaken. Many predate current concepts in glycaemic control and so require fresh interpretation. The objective of the studies of early design was usually to establish whether or not the polyols had adverse influences on metabolism, such as causing FPG, cholesterolaemia or triacylglycerolaemia to increase. For example: no such adverse effects were found in healthy individuals, a mixed group of mainly older
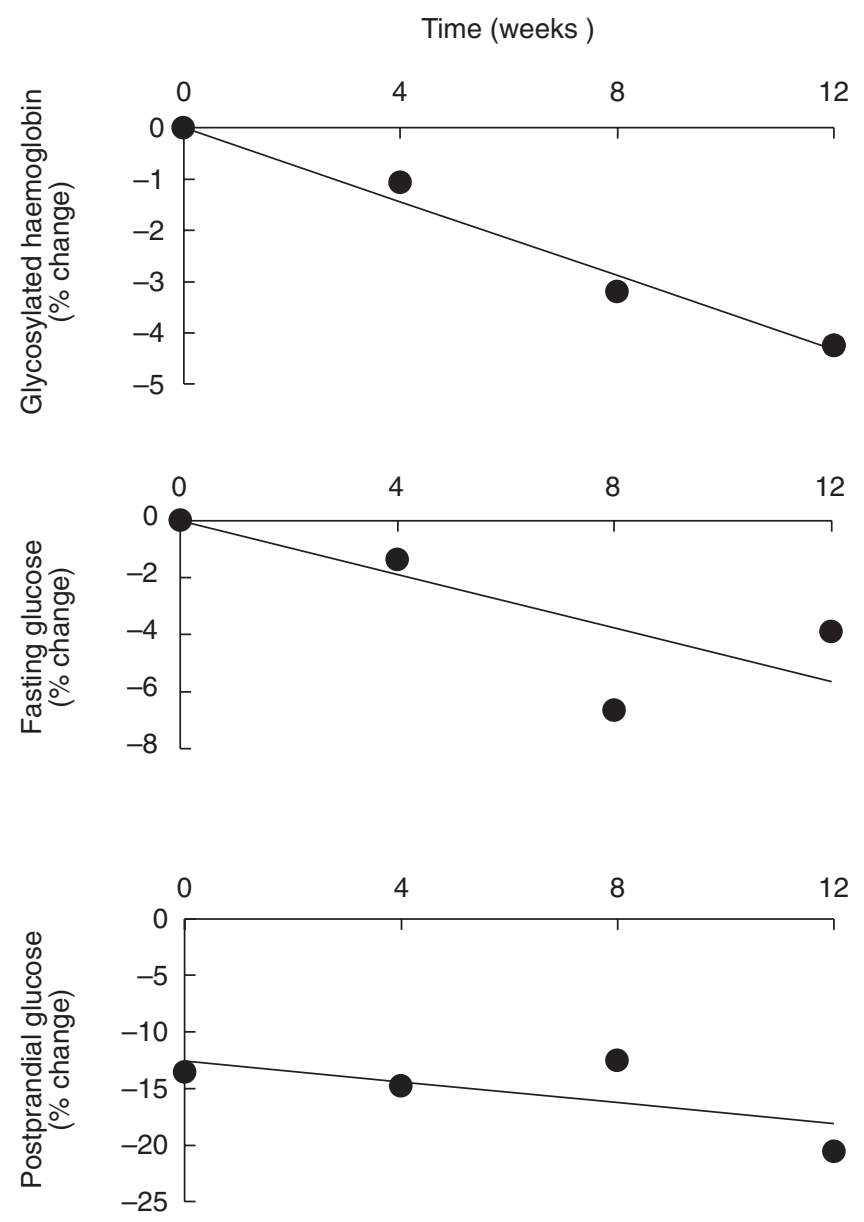

Fig. 6. Improvement in glycaemic control with $6 \mathrm{~g}$ isomalt per meal in type 2 diabetes mellitus (DM) patients. Isomalt was fed to twentyfour subjects, twelve controls and twelve type 2 DM patients, at a rate of $6 \mathrm{~g}$ per meal ( $24 \mathrm{~g}$ daily). Percentage change is $100 \times$ treatment means difference/treatment means average. Means differences discounted the minor difference between treatment groups immediately after randomisation. The regression lines were: $\%$ Glycosylated haemoglobin $=-0.4$ (SE 0.02) $\%$ per week, $P=$ 0.0004

Fasting glucose $=-0.5$ (SE 0.1) \% per week, $P=0.04$;

Postprandial glucose $=(-12.5(\text { SE } 2.7) \%)^{\star}+(-0.5$ (SE 0.4) \% per week)†.

${ }^{*} P=0.04, \dagger P=0.3$. Data for these calculations were from the study of Pometta et al. (1985), which reported the data as figures; tabulated means data were kindly supplied by Palatinit $\mathrm{GmbH}$ (Mannheim, Germany).

schoolchildren (aged $>13$ years) with some adults, when exchanging $50 \mathrm{~g}$ xylitol for sucrose for 2 years (Huttunen $e t$ al. 1975). The reduced GL due to this exchange is estimated to be $30 \mathrm{~g}$ daily, which is substantial. Reduced FPG was not observed, which suggests that the difference in GL is not of great importance in children or possibly young adults with a healthy metabolism. In another study, Abraham et al. (1981) investigated the exchange of $26 \mathrm{~g}$ sucrose for $30 \mathrm{~g}$ maltitol syrup for 4 weeks in type $2 \mathrm{DM}$ patients. No adverse effects were observed and there was also no improvement in glycaemic control as indicated by 
either FPG or fasting insulin, which can reflect the degree of insulin sensitivity and/or B-cell function (Matthews et al. 1985). This is not surprising given the difference in GL between the treatments, estimated at present at just $2 \mathrm{~g}$ daily (due to sucrose, GI $=65$ and $26 \mathrm{~g}$ intake daily $v$. maltitol syrup, GI $=50$ at $30 \mathrm{~g}$ intake daily). Other studies have examined mainly type $1 \mathrm{DM}$ children. The treatments were usually polyol $v$. 'no polyol' and the outcomes were usually no adverse effects on FPG and urinary glucose, for example with sorbitol (Steinke et al. 1961). Assuming the study followed the controlled plan, the supplementary sorbitol treatment group would have had an extra GL of $5 \mathrm{~g}$ daily; thus the study provided no information about the relationship of GI or GL to the degree of control of carbohydrate metabolism. Thannhauser \& Meyer (1929) and Mehnert et al. (1960) undertook similar studies (of early design) in type 2 DM patients. Again no adverse effects of sorbitol (40 g) were observed, but again the experimental designs did not allow an assessment of the relationship between GL and the control of glucose metabolism. Another study was undertaken with parenteral xylitol (30 g daily for 1 week) because of expectations of reduced requirements for insulin secretion. Such treatment with xylitol lowered the FPG in some individuals of a mixed population of type 1 and 2 DM patients (Yamagata et al. 1965, 1969); amongst the type 2 DM patients the present author notes the xylitol to have consistently reduced urinary excretion of glucose, and this almost quantitatively in accordance with the degree of glucosuria observed before treatment.

\section{Scope for replacement of sugars, maltodextrins and glucose syrups}

Even quite small differences in GL due to carbohydrate exchange appear to be important. Thus in well-controlled type $2 \mathrm{DM}$ patients a residual deterioration in plasma $\mathrm{HbA}_{1 \mathrm{c}}$ occurs at an average rate of 0.2 (SEM 0.04) units HbA1c \% per year $(0 \cdot 1,0.2$ and $0.3 \%$ per year in Pometta et al. 1985; Orchard et al. 1990; Wallace \& Matthews, 2000 respectively). Intervention studies with low-GI diets show the reversal of deterioration during the period of study. Assuming linear responses, the minimum change in GL through change in carbohydrate quality needed to reverse the average deterioration is just 12 (SEM 2) g/d. Estimates for individual studies are 11, 8, 13, 19, 9, 14 and $12 \mathrm{~g} / \mathrm{d}$ (for Jenkins et al. 1988; Brand et al. 1991; Wolever et al. 1992a,b (two treatments); Frost et al. 1994; Järvi et al. 1999; Giacco et al. 2000 respectively). Such reversal is seen with the polyol isomalt consumed at $24 \mathrm{~g}$ daily (Fig. $6)$. A similar conclusion arises from the examination of the upper quintiles of GI and advent of DM in men (Salmerón et al. 1997a) and in women (Salmerón et al. 1997b; Meyer et al. 2000), and CHD in women (Liu et al. 2000b). Thus a change in GL due to carbohydrate quality (not quantity) of $10 \mathrm{~g}$ glucose/d corresponds to a change in disease advent of $6,27,10$ and $33 \%$ respectively, with a mean of 19 (SEM 7) $\%(P<0 \cdot 05)$. Such a change in GL by exchanging carbohydrates could readily be achieved by replacing some sugars, maltodextrins and glucose syrups with tolerable amounts of polyols.
The consumption of sucrose in one population of US women ranged from the lowest quintile median of $26 \mathrm{~g} / \mathrm{d}$ to the highest of $57 \mathrm{~g} / \mathrm{d}$, with a similar range for glucose and fructose combined (Meyer et al. 2000). This corroborates similar findings from elsewhere with men consuming more by weight than women in accordance with higher energy intakes (Glinsmann et al. 1986; Henderson et al. 2003). In terms of macronutrient exchange or replacement, it is more relevant to consider intakes per meal (rather than per d) because it is the meal that initiates an impulse to which metabolism responds (Livesey, 2000b). For an average three meals per $d$ these sucrose consumption data correspond to an average meal sucrose intake of 8 to $19 \mathrm{~g} / \mathrm{meal}$; comparative values for glucose are from 4 to $10 \mathrm{~g} / \mathrm{meal}$ (Meyer et al. 2000). Such quantities as polyol are tolerable and many individuals can tolerate more (Livesey, 2001; Marteau \& Flourié, 2001). There is, therefore, a realistic potential for sugar replacers to exchange with sugars making a useful contribution towards a smaller glycaemic response to diet as a whole among those who would choose this approach.

The total replacement of dietary sugars nevertheless would be neither realistic nor expected, and in practice the potential benefit would probably be limited to reducing the upper range of sugar intakes. The range between the lower and upper quintiles in the study of Meyer et al. (2000) was just $10 \mathrm{~g} / \mathrm{meal}$ for sucrose and $7 \mathrm{~g} / \mathrm{meal}$ for glucose, a large part of which could potentially be replaced by polyols whenever desirable.

Food manufacturers will, however, consider foods not meals as products of their manufacture; likewise consumers buy food items, for which there is scope for sugar replacement to achieve reduced glycaemia. About $25 \mathrm{~g}$ per serving in foods is practical; however, usage of lower amounts across a broader range of food products may be more satisfactory. Unfortunately, this possibility is hampered at present by history; regulatory provisions in Europe currently limit the scope of use of sugar replacers (categorised as sweeteners and additives) but not other carbohydrates, which are considered as ingredients (Barlow, 2001; Howlett, 2001). This situation tends to limit the use of sugar replacers to confections and baked goods, and to elevate their content in such foods. A regulation permitting the broader use of polyols, as for low-digestible sugars of similar tolerance, would deserve consideration.

\section{Assignment of polyols and foods to glycaemic index bands}

Foods have GI values that span a continuous broad normal distribution, which can be divided into narrower bands (for example, very low, low, intermediate, high; Table 9). Banding can make it easier in practice for users to select appropriate diets, as noted by Black \& Rayner, for the Coronary Prevention Group (1992), or appropriately lowglycaemic diets for diabetes control (Brand et al. 1991). Brand-Miller et al. (1999) suggest that GI > 70 would indicate a high-GI food while GI $<55$ indicates a low-GI food, with intermediate GI being 55 to 70 . These bands have been demonstrated in practice to be helpful in the selection of a low-GI diet (Brand et al. 1991), which without setting a precise value would just fall into the low-GI band. To 
make a more stringent target for formulating low-GI foods, Bär (2000) recently suggested GI < 40, which here is called 'very-low GI' to avoid confusion with the low-GI band of Brand et al. (1991), Brand-Miller et al. (1999) and which coincidently occurs approximately at the mean less one standard deviation for the normal distribution of food GI values (G. Livesey, unpublished results). Some foods have such low GI values that the carbohydrate assessed inevitably includes unavailable or so-called 'non-glycaemic' carbohydrate (Jenkins et al. 1987; Food and Agriculture Organization, 1998), including resistant starch (Björck et al. 2000) and some polyols. Certain polyols (sorbitol, xylitol) additionally cause low increments in plasma glucose due to slow absorption and metabolism in the liver and, although glucogenic, they give only low glycaemic responses.

The use of nutrient banding to communicate nutritional value is still in its infancy (Black \& Rayner, for the Coronary Prevention Group, 1992). Table 9 simply maps the polyols, fruits, sugars, and candies and snacks to the presently used bands and suggests an additional very-low band for GI based on currently available information.

Regular, intermediate- and higher-maltitol syrups fall into the low-GI band while other polyols fall into the verylow-GI band (erythritol, xylitol, sorbitol, mannitol, isomalt, lactitol, maltitol, high-polymer maltitol syrup, polyglycitol). There is an absence from Table 9 of information on polyols in goods other than confections, such as baked goods or jams. Reduced glycaemia and insulinaemia has been demonstrated in such products (Bakr, 1997) but there is inadequate information across the time course for the calculation of GI and II. It is possible to replace sucrose (and some maltodextrins and glucose syrups) with polyols in baked goods, preserves and candies, but it is not possible to do this with intense sweeteners which lack both volume or bulk mass.

Mixtures of polyols with sugars, fats, starch-based foods and protein-based foods were shown in the present review to yield lower GI than predicted for the component GI values. Until such time as a method is established to predict such lower GI values for the mixture, it is suggested that food products might, when polyol based, have GI values that are estimated from the GI values of the ingredients; this in the same way as GI values of meals are calculated from the GI values of the component foods.

\section{Food energy values of polyols}

Various articles concerned with blood glucose control and dental health report energy values for polyols incorrectly as $17 \mathrm{~kJ}(4 \mathrm{kcal}) / \mathrm{g}$. This value was a supposition based on the approximate heats of combustion of polyols and an assumption that each polyol was fully absorbed and used in metabolism. Numerous investigations have now been undertaken and the polyols have been found to have different values lower than their heats of combustion (Table 10). The basis of derivation of polyol food energy is that carbohydrate absorbed via the small intestine and not excreted in the urine is fully available as energy, while carbohydrate entering the colon and fully fermented is only $50 \%$ available as energy. This basis has widespread support, and so various reviewing bodies have derived similar (though not identical) energy values to those shown in Table 10 (see Livesey et al. 2000). Values obtained by indirect calorimetry

Table 9. Glycaemic index (GI) bands and assignment of polyols, fruits, sugars, and candies and snacks by GI shown*

\begin{tabular}{|c|c|c|c|c|c|c|c|c|}
\hline Band & Polyols & GI & Fruits & Gl & Sugars & Gl & Candies and snacks & Gl \\
\hline High GI (GI >70-140) & & & $\begin{array}{l}\text { Dates (dried) } \\
\text { Watermelon }\end{array}$ & $\begin{array}{r}103 \\
72\end{array}$ & $\begin{array}{l}\text { Maltose } \\
\text { Glucose }\end{array}$ & $\begin{array}{l}105 \\
100\end{array}$ & $\begin{array}{l}\text { Jelly beans } \\
\text { Pretzels } \\
\text { Corn chips }\end{array}$ & $\begin{array}{l}87 \\
83 \\
72\end{array}$ \\
\hline Intermediate $\mathrm{GI}(\mathrm{GI}>55-70)$ & & & $\begin{array}{l}\text { Pineapple } \\
\text { Banana }\end{array}$ & $\begin{array}{l}66 \\
55\end{array}$ & $\begin{array}{l}\text { Sucrose } \\
\text { Honey }\end{array}$ & $\begin{array}{l}65 \\
58\end{array}$ & $\begin{array}{l}\text { Regular candy } \\
\text { Fruit chews } \\
\text { Almond bar } \\
\text { Power chocolate bar } \\
\text { Chocolate confection }\end{array}$ & $\begin{array}{l}70 \\
70 \\
68 \\
58 \\
58\end{array}$ \\
\hline Low GI (GI >40-55) & $\begin{array}{l}\text { Maltitol syrups } \\
\text { Intermediate } \\
\text { Regular } \\
\text { High }\end{array}$ & $\begin{array}{l}53 \\
52 \\
48\end{array}$ & $\begin{array}{l}\text { Grapes } \\
\text { Oranges }\end{array}$ & $\begin{array}{l}54 \\
50\end{array}$ & Lactose & 46 & $\begin{array}{l}\text { Ice-cream } \\
\text { Chocolate } \\
\text { Yoghurt } \\
\text { Popcorn } \\
\text { Chocolate coated toffee } \\
\quad \text { and cookie bar } \\
\text { Chocolate peanut } \\
\quad \text { confection }\end{array}$ & $\begin{array}{l}52 \\
49 \\
46 \\
45 \\
44 \\
41\end{array}$ \\
\hline Very low GI (GI 0-40) & $\begin{array}{l}\text { Polyglycitol } \\
\text { Maltitol syrup } \\
\text { (high-polymer) } \\
\text { Maltitol } \\
\text { Xylitol } \\
\text { Isomalt } \\
\text { Sorbitol } \\
\text { Lactitol } \\
\text { Erythritol } \\
\text { Mannitol }\end{array}$ & $\begin{array}{r}39 \\
\\
36 \\
35 \\
13 \\
9 \\
9 \\
6 \\
0 \\
0\end{array}$ & $\begin{array}{l}\text { Plum } \\
\text { Apple } \\
\text { Cherries }\end{array}$ & $\begin{array}{l}39 \\
38 \\
22\end{array}$ & Fructose & 23 & $\begin{array}{l}\text { Fried chipped potato } \\
\text { Maltitol chocolate } \\
\text { Potato chips (crisps) } \\
\text { Peanuts } \\
\text { Isomalt chocolate } \\
\text { Erythritol chocolate }\end{array}$ & $\begin{array}{r}38 \\
30 \\
23 \\
14 \\
14 \\
2\end{array}$ \\
\hline
\end{tabular}

\footnotetext{
* For references, see Table 8 footnotes and Foster-Powell et al. (2002).
} 
corroborate the formula approach (see also Livesey, $2002 b$ ). Values accepted in the USA under the process of 'self determination' are in reasonable agreement, while European regulations (European Communities, 1990) prescribe a single value for all permitted polyols.

The USA, Canada and Australia considered whether a single value for all polyols might be misleading to the public and allocate separate values to each polyol. In the context of the labelling of individual foods, and in the context of individual food products meeting energy-reduced claims in respect of low-energy food regulations (for example, Codex Alimentarius Commission, 1991), a single energy value is not easily sustainable.

For low-glycaemic foods or dental-remineralising candies and chewing gums made with polyols, it follows that such foods and dentifrices would also be lower in energy than the corresponding product made with sugars, maltodextrins or starches. Thus a candy of $25 \mathrm{~g}$ portion size and made with a polyol of $8 \mathrm{~kJ} / \mathrm{g}$, which may be consumed because it is tooth friendly or low glycaemic or both, would have a food energy content of $200 \mathrm{~kJ}$ compared with $425 \mathrm{~kJ}$ for similar candies based on sugars ( $>50 \%$ energy reduction). For a snack food of $1000 \mathrm{~kJ}$ with the same $25 \mathrm{~g}$ of carbohydrate this ingredient exchange would be a $20 \%$ reduction in energy.

\section{Dental aspects of polyols}

The role of polyols in reducing dental caries may be regarded as a benefit to part of the digestive system and so an aspect of digestive health. Other such aspects are considered further later (p. 182).

Polyols are a poor source of energy for micro-organisms of the oral cavity. Sucrose, other sugars and high-GI starches, by contrast, are readily fermented by oral microorganisms. Such carbohydrates are acidogenic and cause tooth decay (dental caries), whereas polyols effectively do not. For this reason polyols have been described as 'tooth friendly' and are permitted ingredients in sugar-free products (European Communities, 1994).

Five key factors are involved in dental caries: teeth, bacteria, sugar or starch, time and saliva. Bacteria in the mouth reside mainly in dental plaque. Many species reside there but few continue to ferment once a critical low pH of 5.7 is reached. In the main, mutans streptococci (Streptococcus mutans and S. sobrinus) and lactobacilli are involved in acidogenesis (British Nutrition Foundation, 2000). Saliva delivers amylase that may facilitate acidogenesis from starch, but also provides buffer capacity to wash away soluble carbohydrate, acids and immunoglobulins that aggregate bacteria. Other agents in saliva are effective in protecting the body from harmful pathogens: lysozyme digests certain bacteria, lactoferrin binds and deprives bacteria of $\mathrm{Fe}$, sialoperoxidase reacts with $\mathrm{H}_{2} \mathrm{O}_{2}$ and salivary thiocyanate to form a potent antibacterial agent, and hypothiocyanite (British Nutrition Foundation, 2000). Saliva also provides $\mathrm{Ca}$, which supports remineralisation of demineralised teeth. Increased salivary buffer capacity on mastication might contribute to reduced caries incidence and the sweetness of polyols and sugar-free chewing frequency have each been implicated in salivation rate (RuggGunn, 1989; Birkhed \& Bär, 1991; Dodds et al. 1991; Mäkinen et al. 1995, 1996) though direct evidence for this is scant.

Although dental caries has a multifactorial aetiology (Burt \& Ismail, 1986) and has decreased in prevalence from values 40 years ago (König, 1990), it is still a highly prevalent disease. Current evidence indicates that it does not develop without either sugars and starches or bacteria in the mouth (National Research Council, 1989; British Nutrition Foundation, 2000), and cannot occur without an increase in acid production (Bibby, 1975; Burt \& Ismail, 1986). Acidogenesis in human volunteers is measurable routinely by interdental-plaque-pH telemetry (Mühlemann, 1971).

Table 10. Food energy values of polyols (reference: sucrose, maltodextrins, starch at $17 \mathrm{~kJ}(4 \mathrm{kcal}) / \mathrm{g})$

\begin{tabular}{|c|c|c|c|c|c|c|c|c|c|c|}
\hline & \multicolumn{2}{|c|}{$\begin{array}{c}\text { Potential energy } \\
\text { (heat of combustion)* }\end{array}$} & \multicolumn{2}{|c|}{$\begin{array}{c}\text { Formula based on } \\
\text { current availability } \\
\text { data† }\end{array}$} & \multicolumn{2}{|c|}{$\begin{array}{c}\text { Indirect } \\
\text { calorimetry } \ddagger\end{array}$} & \multicolumn{2}{|c|}{$\begin{array}{l}\text { US 'self determined' } \\
\text { and LSRO§ }\end{array}$} & \multicolumn{2}{|c|}{$\begin{array}{l}\text { European } \\
\text { regulations|l }\end{array}$} \\
\hline & $\mathrm{kJ} / \mathrm{g}$ & $\mathrm{kcal} / \mathrm{g}$ & $\mathrm{kJ} / \mathrm{g}$ & $\mathrm{kcal} / \mathrm{g}$ & $\mathrm{kJ} / \mathrm{g}$ & $\mathrm{kcal} / \mathrm{g}$ & $\mathrm{kJ} / \mathrm{g}$ & $\mathrm{kcal} / \mathrm{g}$ & $\mathrm{kJ} / \mathrm{g}$ & $\mathrm{kcal} / \mathrm{g}$ \\
\hline Erythritol & $17 \cdot 2$ & $4 \cdot 1$ & 1 & 0.2 & na & na & 1 & 0.2 & & \\
\hline Isomalt & 17 & $4 \cdot 1$ & 9 & $2 \cdot 1$ & 8 & 2 & 8 & 2 & & \\
\hline Lactitol & 17 & $4 \cdot 1$ & 8 & 2 & 8 & 1.9 & 8 & 1.9 & & \\
\hline Maltitol & 17 & $4 \cdot 1$ & 11 & $2 \cdot 7$ & $11 \rrbracket$ & $2 \cdot 69$ & 9 & $2 \cdot 1$ & & \\
\hline \multicolumn{11}{|l|}{ Maltitol syrups } \\
\hline Regular, intermediate, high & $17 \cdot 1$ & $4 \cdot 1$ & 12 & 3 & na & na & & & 10 & $2 \cdot 4$ \\
\hline High-polymer & $17 \cdot 1$ & $4 \cdot 1$ & 12 & $2 \cdot 8$ & $11 \rrbracket$ & $2 \cdot 6$ ा & 13 & 3 & & \\
\hline Polyglycitol & $17 \cdot 1$ & $4 \cdot 1$ & 12 & $2 \cdot 8$ & na & na & J & & & \\
\hline Mannitol & $16 \cdot 7$ & $4 \cdot 0$ & 6 & 1.5 & na & na & 7 & 1.6 & & \\
\hline Sorbitol & $16 \cdot 7$ & $4 \cdot 0$ & 10 & $2 \cdot 5$ & na & na & 11 & $2 \cdot 7$ & & \\
\hline Xylitol & 17 & $4 \cdot 1$ & 12 & 3 & na & na & 10 & $2 \cdot 4$ & & \\
\hline
\end{tabular}

LSRO, Life Sciences Research Office; na, information not available.

* Potentially available had the polyol been fully available. Heats of combustion are calculated (Livesey, 1992).

† Formula value $=$ heat of combustion $\times$ (available carbohydrate $+0.5 \times$ fermentable carbohydrate) using data from Table 3 .

$\ddagger$ For studies on indirect calorimetry, see van Es et al. (1986), Sinaud et al. (2002) and Livesey (2002a).

$\S$ US 'self determined' labelling values are given with support from LSRO (Life Sciences Research Office, 1994, 1999).

II European Communities (1990).

In Deduced from a high-polymer syrup and its polymer fraction based on Sinaud et al. (2002). 
The technique is used for investigation of the compliance of tooth-friendly products with the requirements of the authority in Switzerland, where sugar-free products are the major form of confectionery (Imfeld, 1983, 1993).

Lack of acidogenic potential in polyols is the major mechanism minimising caries development in polyol-based candies and sweet goods (Table 11). It appears there are no real concerns about adaptation, that is, selection of polyolfermenting acidogenic organisms (Table 11). Adaptation is not completely absent, but does not occur to any extent that would risk caries formation from acidogenesis (Toors, 1992). Acid production in plaque after sugar ingestion follows a characteristic curve, a rapid fall in $\mathrm{pH}$ followed by a slow rise, called a Stephan curve. A fall below the critical $\mathrm{pH}$ of 5.7 puts teeth under carious attack. According to this approach, Imfeld (1993) in his review was able to classify the polyols as either having 'no cariogenic potential' or having 'virtually no cariogenic potential' (see Table 11).

Caries prevention using polyols has been described as a 'passive process' as it is the absence of acidogenic substance rather than the presence of an active or bacteriostatic substance that is important (Imfeld, 1993). However, xylitol may also be bacteriostatic on one and possibly more strains of S. mutans (Waaler et al. 1992). The mechanism proposed was the reversible inhibition of essential metabolic pathways including the accumulation of xylitol-5phosphate, an inhibitor of phosphoenolypyruvate production. The clinical significance has been reported as a reduction in virulence of $S$. mutans and modification of the plaque ecosystem including reductions in plaque quantity and adhesivity (reduced ability to adhere to the hard tissues). The quantitative contribution this makes to caries reduction is reported as unclear by some authors (Isokangas et al. 1991; Scheie et al. 1998; Alanen, 2001). Nevertheless, xylitol is commonly associated with reduced numbers of S. mutans (Hayes, 2001; Mäkinen et al. 2001), appears more effective than erythritol in reducing the mass of plaque in human subjects (Mäkinen et al. 2001), and is more effective than sorbitol in caries prophylaxis (Mäkinen et al. 1996). A difficulty with the interpretation of these comparisons is a lack of quantitative information on the separate roles of saliva stimulation and microbiological factors (Alanen, 2001). Interestingly, the reduced transmission of $S$. mutans from mother to offspring may explain a lower caries incidence in 2- to 5-year-old children after maternal xylitol consumption when the children were aged 3-24 months (Isokangas et al. 2000).

Less well known than the virtually non-acidogenic potential of polyols as sugar replacers is their limitation of plaque formation. Plaque is a conglomerate of bacteria and polysaccharides where acidogenesis takes place. The polysaccharides synthesised by oral bacteria bulk out the plaque, which in turn harbours these organisms and retains fermentation products, so depressing the $\mathrm{pH}$ further and reducing the ability of saliva to wash the organisms and acid away (Newbrun, 1982; Rolla et al. 1985). By contrast polyols are not substrates for polysaccharide and plaque synthesis. Isomalt, while not supplying substrate for polysaccharide synthesis (Bramstedt et al. 1976; Ciardi et al. 1983), might also inhibit this process from sucrose, as evident for some of the longer-chain hydrogenated isomaltooligosaccharides (Tsunehiro et al. 1997). Polysaccharide synthesis is also lower with xylitol, lactitol, mannitol and sorbitol than with sucrose (Grenby et al. 1989).

Polyols also reverse the initial stages of dental caries by promoting remineralisation. This is preferable to tooth restoration except on advanced lesions (Featherstone, 2000). Stimulation of salivary flow facilitates remineralisation when induced between meals by confections containing a polyol; this is evident because the repair of early lesions is greater when such products are ingested than when no food is consumed (Leach, 1987). A recent and important observation is that polyols both slow demineralisation of tooth enamel and accelerate remineralisation of

Table 11. Cariogenic potential, bacteriostasis, inhibition of polysaccharides synthesis, remineralisation and adaptation

\begin{tabular}{|c|c|c|c|c|c|}
\hline & \multirow[b]{2}{*}{$\begin{array}{c}\text { Major (passive) mechanism: } \\
\text { cariogenic potential* }^{*} \\
\text { (based on acidogenesis) }\end{array}$} & \multicolumn{3}{|c|}{ Minor (active) mechanisms } & \multirow[b]{2}{*}{$\begin{array}{l}\text { Concerns: significant } \\
\text { adaptation }\end{array}$} \\
\hline & & Bacteriostasis & $\begin{array}{l}\text { Inhibition of } \\
\text { polysaccharide } \\
\text { synthesis }\end{array}$ & $\begin{array}{c}\text { Promotion } \\
\text { of remineralisation }\end{array}$ & \\
\hline Erythritol & None to virtually none ${ }^{*}$ & - & - & - & - \\
\hline Xylitol & None & Yest & _- & Yes§ & Nonell \\
\hline Sorbitol & Virtually none & - & - & - & Noneq \\
\hline Mannitol & Virtually none & _- & _- & _- & _ \\
\hline Lactitol & None & - & - & - & Nonet† \\
\hline Regular maltitol syrup & Virtually none & - & - & - & Noneł \\
\hline
\end{tabular}

\footnotetext{
* After Imfeld (1993), except eythritol for which a preliminary classification is given here. This reflects the practical inability of oral bacteria to use these carbohydrates for acid production (or for plaque polysaccharide synthesis).

† Waaler et al. (1992). The quantitative contribution of this bacteriostatic mechanism to clinical outcome is unknown, though may explain advantages of xylitol over sorbitol and erythritol (see p. 181).

‡ Ciardi et al. (1983), Bramstedt et al. (1976). Quantitative contribution to clinical outcome is unknown.

$\S$ Takatsuka (2000), Mäkinen et al. (1995).

II Toors (1992), Gehring et al. (1975).

I Toors (1992), Cornick \& Bowen (1972).

** Van der Hoeven $(1979,1980)$.

†† Havenaar et al. (1978).

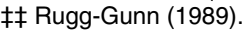


demineralised lesions. Xylitol and particularly isomalt may be effective in this regard (Takatsuka, 2000).

On the basis of substantial studies in human subjects regarding caries the prophylactic properties of lactitol, isomalt and xylitol have been recommended (Imfeld, 1993; Featherstone, 1995; Mäkinen et al. 1996). Clinical trials on sorbitol (Birkhed \& Bär, 1991), maltitol syrup (RuggGunn, 1989) and xylitol (Mäkinen et al. 1996) indicate that they are non-cariogenic. Erythritol has been advanced as a potential new caries preventative (Kawanabe et al. 1992; Mäkinen et al. 2001).

\section{Colonic health aspects}

\section{The colonic environment}

Due to their ease of fermentation by gut flora, lowdigestible carbohydrates are very important in human health. Such carbohydrates contribute fundamentally to the establishment of an anaerobic and acidic environment in the colon. Their fermentation enables saccharolytic anaerobes and aciduric organisms to grow in preference over putrefying, endotoxic, pathogenic, and procarcinogen-activating aerobic organisms (Hawksworth et al. 1971; Brown et al. 1974; Gracey, 1982; Hill, 1985; Hill et al. 1987; Rowland, 1991; Mitsouka, 1992; Screvola et al. 1993a,b; Mital \& Garg, 1995).

Low-molecular-weight carbohydrate (lactulose) and polyol (lactitol) have long been acknowledged for their ability to reduce circulating levels of $\mathrm{NH}_{3}$ and toxic microbial substances, the clinical utility of which is the treatment of hepatic encephalopathy (Blanc et al. 1992).

The acidic conditions associate with or normalise epithelial functions resulting in fewer pathologies and their markers, such as aberrant crypts (Samelson et al. 1985), large adenomas (Roncucci et al. 1993; Ponz de Leon \& Roncucci, 1997; Biasco \& Paganelli, 1999) and possibly tumours (Thornton, 1981). Lactic acid is of particular note; it is generated from all fermentable carbohydrates but especially those that readily undergo microbial glycolysis including polyols. A slow removal of lactic acid from the colon would help to maintain acidity and the growth of aciduric organisms such as the lactic acid bacteria, which are now widely promoted as probiotics. Butyric acid, which can be generated from polyols, sometimes in large amounts (Mortensen et al. 1988; Clausen et al. 1998), and possibly due to secondary fermentation of lactic acid, is widely recognised for its probable role in maintaining a healthy colonic epithelium. It is also recognised for its improvement of inflammatory conditions of the colonic mucosa (Roediger, 1990; Scheppach et al. 1995) and anti-neoplasic activity (Velazquez et al. 1996; Scheppach et al. 2001; for a review, see Brouns et al. 2002). Although faecal butyrate is not especially prominent amongst black South Africans who are renowned for their healthy colons, raised concentrations of short-chain organic acids (Segal et al. 1995) and acidity (Levy et al. 1994) are found in these individuals. This has been attributed to increased fermentation and a higher than usual entry into the colon (than in Westerners) of osmotic carbohydrate (Veitch et al. 1998; Segal, 2002).

These responses can generally be attributed to saccha- rolytic fermentation, ease of fermentation, and water entry into the colon with osmotic carbohydrates; thus responses have been reported for a wide range of low-digestible and fermentable carbohydrates including polyols in human subjects. For example, responses have been reported for lactulose (MacGillivary et al. 1959), lactitol (Felix et al. 1990; Screvola et al. 1993b; Ravelli et al. 1995; Tarao et al. 1995; Ballongue et al. 1997), isomalto-oligosaccharides (Kaneko et al. 1994), lactosucrose (Teramoto et al. 1996), and fructo-oligosaccharides (Gibson \& Roberfroid, 1995; Tuohy et al. 2001). Gibson \& Roberfroid (1995) have reported responses for inulin, Zhong et al. (2000) for polydextrose and Bird et al. (2000) for some resistant starches. For individuals with disaccharidase deficiencies, similar reports appear for lactose (Segal, 1998, 2002) and sucrose (Veitch et al. 1998; Segal, 2002), and incomplete absorption of fructose (Segal, 1998). Short-chain organic acids may also modify gastrointestinal motility and so could have a role in maintaining a regular bowel habit (Cherbut et al. 1998; Piche et al. 2000).

\section{Constipation and laxation}

Constipation may be defined most simply as 'less than three bowel movements per week' and is the most common gastrointestinal complaint in Western cultures, triggering considerable use of over-the-counter laxatives and consultations with medical practitioners (Royal College of General Practitioners, 1986; Sandler et al. 1990; Sweeney, 1997). It is particularly common in the elderly (Koch \& Hudson, 2000), diabetics (Haines, 1995), children (Guimaraes et al. 2001) particularly those with developmental and neurological disability (Staiano et al. 2000; Tse et al. 2000), pregnancy (Signorelli et al. 1996), and in those with reduced food intake (anorexia, weight reduction, hospitalisation). It is also common in numerous other less prevalent circumstances (Baker et al. 1999; Nurko et al. 2001). Some drugs are causative, including the commonly used Al antacids and dietary Fe supplements (Baker et al. 1999).

Laxation is the 'gentle stimulation of the bowel to render the motion slightly soft without causing any gripes' (Macpherson, 1990). Laxative action has been established for acceptable intakes of xylitol, sorbitol, mannitol, isomalt, lactitol, maltitol and erythritol (Brin \& Miller, 1974; Sheinin et al. 1974; Ornskov et al. 1988; Livesey, 2001; Marteau \& Flourié, 2001). All act to promote hydration of the colonic contents. Usefully, polyols are obtainable by the public in tasty food items such as sugar-free, reducedenergy candies and other products. Studies have demonstrated the efficacy of polyols (crystalline or syrup formulations) in the elderly (Lederle et al. 1990) and in a multicentred study of the elderly both hospitalised and outpatients (Delas et al. 1991; Sacchetta et al. 2000), and in children (Ornskov et al. 1988; Pitzalis et al. 1996). Data from Spengler et al. (1987) indicate approximately $30 \%$ less constipation even amongst young adults with 'healthy colonic function' consuming up to $48 \mathrm{~g}$ isomalt daily (thirty subjects, $84 \mathrm{~d}$ each), and without excess laxation. Also, lactitol and lactulose each show a reduced likelihood of slow transit occurring in physically inactive hospitalised individuals with healthy gastrointestinal tracts (Pontes et al. 1995). 
Adequate drinking water has been recommended along with dietary fibre to enhance laxation (Gray, 1995; Anti et al. 1998). However, even this dual action may be inadequate (Benton et al. 1997). Rural South African and Asian diets are thought ideal for optimal stool formation. However, osmotic carbohydrate in these diets may be just as important as dietary fibre due to sucrase and lactase 'deficiency' in these populations (Veitch et al. 1998; Segal, 2002) promoting an adequate hydration of colonic contents. Westerners without lactase and sucrase deficiency could, logically, achieve the same goal with appropriate intakes of polyols.

A consensus of food and nutritional scientists and physicians has been established for polyol consumption: 'Each individual may experiment with intake amounts and make adjustments based on their own experience - as they may do routinely with everyday foods having the same effects when eaten to excess' (Salford Symposium Consensus, 2001). This was recommended because individuals vary in the magnitude of their response to polyol ingestion, as indeed they do in the degree to which constipation is experienced. Physicians have also recommended that individuals 'adjust the dose of polyol to a daily bowel movement for 1 to 2 months' (Baker et al. 1999; Nurko et al. 2001).

\section{Tolerance}

Low- and very-low glycaemic-carbohydrate foods can be a cause of unwanted gastrointestinal responses in sensitive individuals or when ingested to excess due to their reaching the colon. Increased gastrointestinal awareness is commonly experienced with high-fibre foods, some of which are low-glycaemic-carbohydrate foods such as beans, lentils and legumes. Other foods include cabbage, Brussels sprouts, brown bread, oatmeal porridge, rough-seeded fruits, honey, tamarinds, figs, prunes, raspberries, strawberries, stewed apples, aloes, rhubarb, cascara and senna (Macpherson, 1990; Friedman, 1991) and modest levels of fibre supplements (Stevens et al. 1987). Similar responses can occur without a change in food source by lowering of the GI using pharmacological means; the sucrase inhibitor acarbose results in elevated flatulence in up to $43 \%$ of consumers and osmotic diarrhoea or laxation in up to $27 \%$ (Sels et al. 1998). All such foods and carbohydrates can be a cause of increased colonic fermentation, flatulence, bloating and cramp. Feelings of bloating (as opposed to measurements of abdominal distension) are probably more common after overingestion of food in general, which is all too common. Furthermore, cramp appears to be secondary to faecal impaction in those with a poor bowel habit (McRorie et al. 2000), or in individuals with irritable bowel syndrome (Briet et al. 1995). In contrast to infectious diarrhoea, watery stools due to colonic fermentation of low-digestible carbohydrates are not a medical issue, and intakes of polyols comparable or greater than normal for dietary fibre are possible (Steinke et al. 1961; Sheinin et al. 1974; Spengler et al. 1987; Sinaud et al. 2002; A Lee, DN Storey, F Bornet and F Brouns, unpublished results).

Rapid transition from a diet that encourages constipation (diets low in polyols, dietary fibre and some slimming diets) to ones that promote laxation (high polyol, dietary fibre and high food intakes) may be a transient cause of discomfort (see McRorie et al. 2000). This may be avoided by varying the daily intake of polyol-based foods gradually over a period of 1 to 4 weeks (see Steinke et al. 1961; Baker et al. 1999; Salford Symposium Consensus, 2001; Nurko et al. 2001). Adaptation to polyols usually improves gastrointestinal tolerance (Tucker et al. 1981; Pometta et al. 1985; Briet et al. 1997) and may in part be psychological (Tucker et al. 1981) and occur with an increasing experience of fermentable carbohydrate consumption (Briet et al. 1997). Tolerance and intakes are greatest when polyols are consumed at regular intervals throughout the day (Livesey, 2001; Sinaud et al. 2002) as may be desirable in some diabetics (Warshaw \& Powers, 1999). Consuming polyols in or with other foods will also improve tolerance by delaying stomach emptying (Livesey, 1990a, 2001; Marteau \& Flourié, 2001). In this respect the co-ingestion of a highcereal-fibre diet may be useful as it provides a matrix with which water combines to be retained in the large bowel. Some individuals are sensitive to polyols and should reduce or even avoid such foods altogether (Salford Symposium Consensus, 2001). Children more than younger or older adults are likely to consume larger amounts of freely available polyols; there is, however, no evidence that children are less able to tolerate polyols than are adults in terms of the weight of polyol per meal or d (Spengler et al. 1987; Paige et al. 1992; A Lee, Salford University, personal communication).

The scientific interpretation of consumer responses to polyols is difficult. Consumers generally indicate that they have diarrhoea whenever they notice a softening of their stool independently of whether it is inconveniencing and some $98 \%$ of such occurrences do not meet commonly accepted criteria for clinical diarrhoea (McRorie et al. 2000). In agreement, a market survey of 1000 consumers of sugar-free products (polyols) has indicated that as little as $0.5 \%$ of individuals make unprompted claims to the experience of adverse gastrointestinal responses (Stewart, 2001). This coincides with the rate observed in the absence of polyol consumption (Steinke et al. 1961; Spengler et al. 1987). Reported responses to polyols are often based on questionnaires that prompt volunteers to notice symptoms of intolerance, and so may be biased; thus when prompted such claims may increase five-fold (Stewart, 2001). Also the interpretation of scientific studies in a laboratory setting can be difficult due to substantial inter-individual variation in gastrointestinal responses to polyols (Livesey, 2001), adaptation (Marteau \& Flourié, 2001) and other reasons (Barlow, 2001).

There are probably more non-diabetics who consume polyols than diabetics, though the latter have often been the subject of study. The American Diabetes Association (2001) has suggested, bearing in mind the varied responses among individuals, that the choice to consume particular types of carbohydrate including polyols must be an individual one, taking account of global dietary guidance and individual metabolic needs. Constipation can be common in diabetics and older individuals (Wegener et al. 1990) and older diabetics may indicate that polyol consumption improves bowel habit (Pometta et al. 1985). Idiopathic 
diarrhoea also occurs in diabetics, but is not due to the increased use of polyols, and polyols are not contraindicated in diabetics when consumed in moderate amounts (Verina et al. 1995). Individuals with type 2 DM tolerate polyols equally as well as normal individuals (Zumbé \& Brinkworth, 1992; Verina et al. 1995).

\section{Conclusion}

Polyols are found to provide acknowledged examples of clinical benefits in the treatment and regulation of bowel habit, and in the conditioning of the colonic environment. Intriguingly, appropriate consumption of low-digestible osmotic carbohydrates may be critically important in Westerners to achieve stool consistencies comparable with those of rural South Africans. These benefits add to the acknowledged properties of polyols as reduced-energy carbohydrates and to the benefits of tooth friendliness, where polyols may have a role in the repair as well as the prevention of caries. The low- to very-low-glycaemic and insulinaemic properties of polyols offer further potential health benefits on replacement of bulk in sugars, syrups and maltodextrins in foods for individuals with both normal and abnormal carbohydrate metabolism. Scope exists for such benefit within gastrointestinal tolerances, which can be improved by attention to the dose, timing, and diet during polyol consumption .

Information on the glycaemic and insulinaemic responses to polyol-based foods is scarce compared with information on polyols alone. Nevertheless, it is evident that interactions between polyols and macronutrients tend to reduce postprandial glycaemia, and interactions between sugars and fats that elevate postprandial insulinaemia can be attenuated or almost abolished using polyols. There is no reason to suppose that long-term use of polyols elevates protein glycation, a marker of glycaemic control, as do high-glycaemic carbohydrates, and there is evidence that the consumption of a polyol might reduce protein glycation, adding to similar observations for other low-glycaemic-carbohydrate diets.

On a technical note, as with carbohydrate foods tabulated in the international tables of GI (Foster-Powell et al. 2002), where data are available on polyols it is found acceptable to pool information on GI values from normal, type 1 and $2 \mathrm{DM}$ patients to obtain a single value for each polyol applicable in all these conditions. Similarly, there is no more dose-dependency of GI values for polyols than for other carbohydrates.

\section{Acknowledgements}

This analysis and review was commissioned by the European Polyol Association, to whom the author is grateful for support. Thanks are due to Keir J. Livesey, Independent Nutrition Logic, for support and discussion of statistical issues.

\section{References}

Abraham RR, Davis M, Yudkin J \& Williams R (1981) Controlled clinical trial of a new non-calorigenic sweetening agent. Journal of Human Nutrition 35, 165-172.
Adcock LH \& Grey CH (1957) The metabolism of sorbitol in the human subject. Biochemical Journal 65, 554-560.

Akgün S \& Ertel NH (1980) A comparison of carbohydrate metabolism after sucrose, sorbitol and fructose meals in normal and diabetic subjects. Diabetes Care 3, 582-585.

Alanen P (2001) Does chewing explain the caries-preventative results with xylitol. Journal of Dental Research 80, 1600-1601.

Alberti KG \& Zimmet PZ (1998) Definition, diagnosis and classification of diabetes mellitus and its complications. Part 1: Diagnosis and classification of diabetes mellitus provisional report of a WHO consultation. Diabetes Medicine 15, 539-553.

Altman DG (1991) Practical Statistics for Medical Research. London: Chapman and Hall.

American Association of Cereal Chemists (2001) The Definition of Dietary Fiber. Report of the Dietary Fiber Definition Committee. St Paul, MN: American Association of Cereal Chemists.

American Diabetes Association (2001) Postprandial blood glucose (a consensus statement). Diabetes Care 24, 775-778.

American Diabetes Association (2002) Evidence-based nutrition principles and recommendations for the treatment and prevention of diabetes and related complications. Diabetes Care 25, S50-S60.

Anti M, Pignataro G, Armuzzi A, Valenti A, Iascone E, Marmo R, Lamazza A, Pretaroli AR, Pace V, Leo P, Castelli A \& Gasbarrini G (1998) Water supplementation enhances the effect of high-fibre diet on stool frequency and laxative consumption in adult patients with functional constipation. Hepatogastroenterology 45, 727-732.

Australia New Zealand Food Authority (2001) Inquiry Report: Derivation of Energy Factors. Canberra, Australia: ANZFA.

Bachmann W, Haslbeck M, Spengler M, Schmitz H \& Mehnert H (1984) Untersuchungen zur Stoffwechselbeeinflussung durch akute Palatinitgaben. Vergleich zu Fructose und Saccharose bei Typ-II-Diabetes (Investigations of the metabolic effects of acute doses of Palatinit. Comparison with fructose and sucrose in Type II diabetes). Aktulle Ernährungsmedizin 9, 65-70.

Baker SS, Liptak GS, Colletti RB, Croffie JM, Di Lorenzo C, Ector W \& Nurko S (1999) Constipation in infants and children: evaluation and treatment. A medical position statement of the North American Society for Pediatric Gastroenterology and Nutrition. Journal of Pediatric Gastroenterology and Nutrition 29, 612-626.

Bakr AA (1997) Application potential for some sugar substitutes in some low energy and diabetic foods. Nahrung-Food 41, s170-s175.

Ballongue J, Schumann C \& Quignon P (1997) Effect of lactulose and lactitol on colonic microflora and enzymatic activity. Scandinavian Journal of Gastroenterology 32, Suppl. 222, 41-44.

Bär A (1990) Factorial calculation model for the estimation of the physiological caloric value of polyols. In Caloric Evaluation of Carbohydrates, pp. 209-257 [N Hosoya, editor]. Tokyo: Research Foundation for Sugar Metabolism.

Bär A (2000) Foods Intended for Use in a Carbohydrate Controlled Diet. Position paper for German Diätvertband. Basel, Switzerland; Bioresco.

Barlow S (2001) Workshop: regulatory affairs. British Journal of Nutrition 85, Suppl. 1, S63-S64.

Bastyr EJ, Stuart CA, Brodows RG, Schwartz S, Graf CJ, Zagar A \& Robertson KE (2000) Therapy focussed on lowering postprandial glucose, not fasting glucose, may be superior for lowering $\mathrm{HBA}_{1 \mathrm{c}}$. Diabetes Care 23, 1236-1241.

Beaugerie L, Fourié B, Marteau P, Pellier P, Franchisseur C \& Rambaud J-C (1990) Digestion and absorption in the human intestine of three sugar alcohols. Gastroenterology 99, $717-723$. 
Bellisle F (2001) Glycaemic Index and Health: the Quality of the Evidence. Montrouge, France: John Libbey, Eurotext.

Benton JM, O'Hara PA, Chen H, Harper DW \& Johnston SF (1997) Changing bowel hygiene practice successfully: a program to reduce laxative use in a chronic care hospital. Geriatric Nurse 18, 12-17.

Bernier JJ \& Pascal G (1990) The energy value of polyols (sugar alcohols). Medicine et Nutrition 26, 221-238.

Bernt WO, Borzelleca JF, Lamm G \& Munro IC (1996) Erythritol: a review of biological and toxicological studies. Regulatory Toxicology and Pharmacology 24, s191-s197.

Biasco G \& Paganelli GM (1999) European trials on dietary supplementation for cancer prevention. Annals of the New York Academy of Sciences 889, 152-156.

Bibby B (1975) The cariogenicity of snack foods and confections. Journal of the American Dental Association 90, 121-132.

Bird AR, Brown IL \& Topping DL (2000) Starches, resistant starches, the gut microflora and human health. Current Issues in Intestinal Microbiology 1, 25-37.

Birkhed D \& Bär A (1991) Sorbitol and dental caries. World Review of Nutrition and Dietetics $\mathbf{6 5}, 1-37$.

Björck I, Liljeberg H \& Östman E (2000) Low-glycaemic index foods. British Journal of Nutrition 83, Suppl. 1, S149-S155.

Black A \& Rayner M, for the Coronary Prevention Group (1992) Just read the label: understanding nutrition information in numeric, verbal and graphic format. London: H.M. Stationery Office.

Blanc P, Daures JP, Rouillon JM, Peray, P, Pierrugues R, Larrey D, Gremy F \& Michel H (1992) Lactitol or lactulose in the treatment of chronic hepatic encephalopathy: results of a metaanalysis. Hepatology (Baltimore) 15, 222-228.

Bornet FRJ, Blayo A, Dauchy F \& Slama G (1996a) Plasma and urine kinetics of erythritol after oral ingestion by healthy humans. Regulatory Toxicology and Pharmacology 24, s220-s285.

Bornet FRJ, Blayo A, Dauchy F \& Slama G (1996b) Gastrointestinal response and plasma and urine determinations in human subjects given erythritol. Regulatory Toxicology and Pharmacology 24, s296-s302.

Bornet FRJ, Costagliola D, Rizkalla SW, Blayo A, Fontvieille AM, Haardt MJ, Letanoux M, Tchobroutsky G \& Slama G (1987) Insulinemic and glycemic indices of six starch-rich foods taken alone and in a mixed meal by type 2 diabetics. American Journal of Clinical Nutrition 45, 588-595.

Bramstedt F, Gehring F \& Karle EJ (1976) Comparative Study of the Cariogenic Effects of Palatinit, Xylitol and Saccharose in Animals. Würzburg, Germany: University of Würzburg.

Brand J, Colagiuri S, Crossman S, Allen A, Roberts D \& Truswell S (1991) Low-glycemic index foods improve long-term glycaemic control in NIDDM. Diabetes Care 14, 95-101.

Brand-Miller J, Wolever TMS, Colagiuri S \& Foster-Powell K (1999) The Glucose Revolution. New York: Marlow \& Company.

Briet F, Achour L, Fourié B, Beaugerie L, Pellier P, Franchisseur C, Bornet F \& Rambaud JC (1995) Symptomatic response to varying levels of fructooligosaccharides consumed occasionally or regularly. European Journal of Clinical Nutrition 49, 501-507.

Briet F, Pochart P, Marteau P, Flourie B, Arrigoni E \& Rambaud JC (1997) Improved clinical tolerance to chronic lactose ingestion in subjects with lactose intolerance: a placebo effect? Gut 41, 632-635.

Brin M \& Miller OM (1974) The safety of oral xylitol. In Sugars in Nutrition, pp. 591-606 [HL Sipple and KW McNutt, editors]. New York: Academic Press.

British Nutrition Foundation (2000) Oral Health, Diet and Other Factors. The Report of the British Nutrition Foundation's Task Force. Amsterdam: Elsevier.
Brooks SPJ (1995) Report on the Energy Value of Sugar Alcohols. Ottawa, Canada: Ministry of Health.

Brouns F, Kettlitz B \& Arrigoni E (2002) Resistant starch and the 'butyrate revolution'. Trends in Food Science and Technology 13, 251-261.

Brown R, Gibson JA, Sladen GE, Hicks B \& Dawson AM (1974) Effects of lactulose and other laxatives on ileal and colonic $\mathrm{pH}$ as measured by radiotelemetry device. Gut 15, 999-1004.

Burt A \& Ismail AI (1986) Diet, nutrition, and food cariogenicity. Journal of Dental Research 65, 1475-1484.

Buyken AE, Toeller M, Heitkamp G, Irsiglert C, Hollert F, Santeusanio F, Stehle P, Fuller JH and the EURODIAB IDDM Complication Study Group (2000) Carbohydrate sources and glycaemic control in type 1 diabetes mellitus. Diabetic Medicine 17, 351-359.

Buyken AE, Toeller M, Heitkamp G, Karamanos B, Rottiers R, Muggeo M, Fuller JH and the EURODIAB IDDM Complications Study Group (2001) Glycaemic index of the diet of European outpatients with type-1 diabetes: relations to glycated hemoglobin and serum lipids. American Journal of Clinical Nutrition 73, 574-581.

Canadian Diabetes Association (2000) Guidelines for the management of diabetes mellitus in the new millennium. Canadian Journal of Diabetes Care 23, 56-69.

Cherbut C, Ferrier L, Roze C, Anini Y, Blottiere H, Lecannu G \& Galmiche JP (1998) Short-chain fatty acids modify colonic motility through nerves and polypeptide YY release in the rat. American Journal of Physiology 275, G1415-G1422.

Ciardi J, Bowen WH, Rolla G \& Nagorski K (1983) Effects of sugar substitutes on bacterial growth, acid production and glucan synthesis. Journal of Dental Research 62, 182.

Clausen MR, Jørgensen J \& Mortensen PB (1998) Comparison of diarrhea induced by ingestion of the fructo-oligosaccharide idolax and the disaccharide lactulose. Digestive Diseases and Sciences 43, 2696-2707.

Codex Alimentarius Commission (1991) Codex Standard for Formula Foods for Use in Weight Control Diets. Codex Standard 181. Rome: Food and Agricultural Organization.

Collier GR, Greenberg GR, Wolever TMS \& Jenkins DJA (1988) The acute effect of fat on insulin secretion. Journal of Clinical Endocrinology and Metabolism 66, 323-326.

Collier GR, Wolever TMS, Wong GS \& Josse RG (1986) Prediction of glycaemic responses to mixed meals in noninsulin dependent diabetic subjects. American Journal of Clinical Nutrition 44, 349-352.

Cornick DER \& Bowen WH (1972) The effect of sorbitol on the dental plaque in monkeys (Macacac Irus). Archives of Oral Biology 17, 1637-1648.

Delas N, Gislon J, Glikmanas M, Henri-Biabaud E, Lemerez M, Licht H, Slama JL \& Gillaume PN (1991) Lactitol in the treatment of constipation in the adult. Open, non-comparative study of its efficacy and its clinical and biological tolerance. Annals of Gastroenterology and Hepatology (Paris) 27, 231-233.

Diabetes UK (2000) Diet in diabetes care. www.diabetes.org.uk/summer 00/diet.htm

Diabetes UK (2002) Nutritional guidelines in diabetes care. www.diabetes.org.uk/infocentre/carerec/nutrition.htm

Dills WL (1989) Sugar alcohols as bulk sweeteners. Annual Review of Nutrition 9, 161-186.

Dodds MW, Hsieh SC \& Johnson DA (1991) The effect of increased mastication by daily gum-chewing on salivary gland output and dental plaque acidogenicity. Journal of Dental Research 70, 1474-1478.

Doorenbos H (1977) Metabolism of Lactitol. Arkelsedijk, The Netherlands: PURAC Biochem BV, Gorinchem.

Drost H, Gierlich P, Spengler M \& Jahnke K (1980) Blutglucose and Seruminsulin nach oraler Applikation von Palatinit im 
Vergleich zu Glucose bei Diabetikern vom Erwachsenentyp (Blood glucose and serum insulin after oral administration of Palatinit in comparison with glucose in diabetics of the lateonset type). Verhandlungen der Deutschen Gesellschaft für innere Medizin 86, 978-981.

Drost H, Spengler M, Kleophas W, Schmitz H \& Jahnke K (1985) Comparative study of the effect of a standardised breakfast containing sorbitol, fructose or sucrose in type-II diabetes mellitus. Aktulle Ernährungsmedizin 10, 195-198.

Dutch Nutrition Council (1987) The Energy Values of Polyols. Recommendations of the Committee on Polyols. The Hague: Nutrition Council.

Ellis FW \& Krantz JC (1941) Sugar alcohols XXII. Metabolism and toxicity studies with mannitol and sorbitol in man and animals. Journal of Biological Chemistry 141, 147-151.

Ellis FW \& Krantz JC (1943) Sugar alcohols XXIV. The metabolism of sorbitol in diabetes. Annals of Internal Medicine 18, 792-796.

European Association for the Study of Diabetes (1995) Recommendations for healthcare professionals in the nutritional management of patients with diabetes. Diabetes, Nutrition and Metabolism 8, 186-189.

European Association for the Study of Diabetes (2000) Recommendations for the nutritional management of patients with diabetes mellitus. European Journal of Clinical Nutrition 54, 353-355.

European Communities (1990) Directive 90/496/EC: nutrition labelling for foodstuffs. Official Journal of the European Communities L276, 40-44.

European Communities (1994) Directive 94/35/EC: sweeteners for use in foodstuffs. Official Journal of the European Communities L237, 2-12.

European Diabetes Policy Group (1999a) A desktop guide to type1 (insulin dependent) diabetes mellitus. Diabetes Medicine 16, 253-266.

European Diabetes Policy Group (1999b) A desktop guide to type2 diabetes mellitus. Diabetes Medicine 16, 716-730.

Featherstone JDB (1995) Effect of isomalt sweetener on the caries process: a review. Journal of Clinical Dentistry 5, 82-85.

Featherstone JDB (2000) The science and practice of caries prevention. Journal of the American Dental Association 131, 887-899.

Felber JP, Tappy L, Vouillamoz D, Radin JP \& Jéquier E (1987) Comparative study of maltitol and sucrose by means of continuous indirect calorimetry. Journal of Enteral and Parenteral Nutrition 11, 250-254.

Felix YF, Hudson MJ, Owen RW, Ratcliffe B, van Es AJH, nan Velthuijsen JA \& Hill MJ (1990) Effect of dietary lactitol on the composition and metabolic activity of the intestinal microflora in the pig and in humans. Microbial Ecology Health and Disease 3, 259-267.

Food and Agriculture Organization (1996-1999) Food and Nutrition Paper no. 52, addenda 4-7. Rome: Food and Agriculture Organization.

Food and Agriculture Organization (1998) Carbohydrates in Human Nutrition. Food and Nutrition Paper no. 66. Rome: Food and Agriculture Organization.

Ford ES \& Liu S (2001) Glycemic index and serum high-density lipoprotein cholesterol concentration among US adults. Archives of Internal Medicine 161, 572-576.

Foster-Powell K, Holt SH \& Brand-Miller JC (2002) International table of glycaemic index and glycaemic load: 2002. American Journal of Clinical Nutrition 76, 5-56.

Friedman G (1991) Diet and the irritable bowel syndrome. Gastroenterology Clinics of North America 20, 313-324.

Frost G, Leeds A, Trew G, Margara R \& Dormhorst A (1998) Insulin sensitivity in women at risk of coronary heart disease and the effect of a low-glycaemic diet. Metabolism 47, 1245-1251.
Frost G, Leeds AA, Doré CJ, Maderios S, Brading S \& Dornhorst A (1999) Glycaemic index as a determinant of serum HDL cholesterol concentration. Lancet 353, 1045-1048.

Frost G, Wilding J \& Beecham J (1994) Dietary advice based on the glycaemic index improves dietary profile and metabolic control in type 2 diabetic patients. Diabetes Medicine 11,397-401.

Gee JM, Cooke D, Gorick S, Wortley GM, Greenwood RH, Zumbé A \& Johnson IT (1991) Effects of conventional sucrosebased, fructose-based and isomalt-based chocolates on postprandial metabolism in non-insulin-dependant diabetics. European Journal of Clinical Nutrition 45, 561-566.

Gehring F, Mäkinen KK, Larmas M \& Scheinin A (1975) Turku sugar studies. X. Occurrence of polysaccharide forming streptococci and ability of mixed plaque microbiota to ferment various carbohydrates. Acta Odontologica Scandinavica 70, Suppl., 223-237.

Giacco R, Parillo M, Rivellse AA, Lasorella G, Giacco A, D'Episcopo L \& Richardi G (2000) Long-term dietary treatment with increased amounts of fibre rich low glycaemic natural foods improves blood glucose control and reduces the number of hypoglycaemic events in type 1 diabetic patients. Diabetes Care 23, 1461-1466.

Gibson GR \& Roberfroid MB (1995) Dietary modulation of the human colonic microbiota. Introducing the concept of prebiotic. Journal of Nutrition 125, 1401-1412.

Gilbertson HR, Brand-Miller JC, Thorburn AW, Evans S, Chondros P \& Werther GA (2001) The effect of flexible low glycemic index dietary advice versus measured carbohydrate exchange diets on glycemic control in children with type 1 diabetes. Diabetes Care 24, 1137-1143.

Glinsmann WH, Irausquin H \& Park YK (1986) Evaluation of health aspects of sugars contained in carbohydrate sweeteners. Report of Sugars Task Force, 1986. Journal of Nutrition 116, Suppl. 11, s1-s216.

Gracey M (1982) Intestinal microflora and bacterial growth in early life. Journal of Pediatric Gastroenterology and Nutrition 1, 13-22.

Gray DS (1995) The clinical uses of dietary fiber. American Family Physician 51, 419-426.

Grenby TH, Phillips A \& Mistry M (1989) Studies of the dental properties of lactitol compared with five other bulk sweeteners in vitro. Caries Research 23, 315-319.

Grimble GK, Patil DH \& Silk DBA (1988) Assimilation of lactitol, an unabsorbed disaccharide, in the normal human colon. Gut 29, 1666-1671.

Guimaraes EV, Goulart EM \& Penna FJ (2001) Dietary fiber intake, stool frequency and colonic transit time in chronic functional constipation in children. Brazilian Journal of Medical Biology and Research 34, 1147-1153.

Haines ST (1995) Treating constipation in the patient with diabetes. Diabetes Education 21, 223-232.

Hassinger W, Sauer G, Cordes U, Krause U, Beyer J \& Baessler KH (1981) The effect of equicaloric amounts of xylitol, sucrose and starch on insulin requirements and blood glucose levels in insulin-dependent diabetes. Diabetologia 21, 37-40.

Havenaar R, Huis in't Veld JHJ, Baker-Dirks O \& Stoppelaar JD (1978) Health and sugar substitutes. In Proceedings of the ERGOB Conference on Sugar Substitutes, Geneva, pp. 192-218 [B Guggenheim, editor]. Basel, Switzerland: Karger.

Hawksworth G, Drasar BS \& Hill MJ (1971) Intestinal bacteria and the hydrolysis of glycosidic bonds. Journal of Medical Microbiology 41, 451-459.

Hayes C (2001) The effect of non-cariogenic sweeteners on the prevention of dental caries: a review of the evidence. Journal of Dental Education 65, 1106-1109.

Henderson L, Gregory J, Irving K \& Swan G (2003) The National Diet and Nutrition Survey: Adults Aged 19-64 Years. London: TSO. 
Herman RH (1974) Hydrolysis and absorption of carbohydrates, and adaptive responses of the jejunum. In Sugars in Nutrition, pp. 145-172 [HL Sipple and KW McNutt, editors]. New York: Academic Press Inc.

Hill MJ (1985) Bacteria and colorectal adenomas. Topics in Gastroenterolology 13, 237-252.

Hill MJ, Melville D, Lennard-Jones J, Neale K \& Richie JK (1987) Faecal bile acids, dysplasia and carcinoma in ulcerative colitis. Lancet ii, 185-186.

Holt SHA, Miller JCB \& Petocz P (1997) An insulin index of foods: the insulin demand generated by $1000-\mathrm{kJ}$ portions of common foods. American Journal of Clinical Nutrition 66, $1264-1276$.

Howlett J (2001) Low-digestible carbohydrates - the regulatory framework. British Journal of Nutrition 85, Suppl. 1, S55-S58.

Hyams JS (1983) Sorbitol intolerance: an unappreciated cause of functional gastrointestinal complaints. Gastroenterology 84, $30-33$.

Huttunen KJ, Mäkinen KK \& Scheinin A (1975) Effects of sucrose, fructose and xylitol diets on glucose, lipid and urate metabolism. Acta Odontologica Scandinavica 70, 239-245.

Imfeld T (1983) Identification of Low Caries Risk Dietary Components. Basel, Switzerland: Karger Verlag.

Imfeld T (1993) Efficacy of sweeteners and sugar substitutes in caries prevention. Caries Research 27, Suppl. 1, 50-55.

International Diabetes Institute Australia (2002) Diabetes prevention programs: eat well live well. www.diabetes.com.au/living_with/healthpromotion.htm

Ishikawa M, Miyashita M, Kawashima Y, Nakamura T, Saitou N \& Modderman J (1996) Effects of oral administration of erythritol on patients with diabetes. Regulatory Toxicology and Pharmacology 24, s303-s308.

Isokangas P, Söderling E, Pienihäkkinen K \& Alanen P (2000) Occurrence of dental decay in children after maternal consumption of xylitol chewing gum, a follow-up from 0 to 5 years of age. Journal of Dental Research 79, 1885-1889.

Isokangas P, Tenovuo J, Söderling E, Männistö H \& Mäkinen KK (1991) Dental caries and mutans streptococci in the proximal area of molars affected by the habitual use of xylitol chewing gum. Caries Research 25, 444-448.

Järvi AE, Karlström BE, Granfeldt YE, Björck IE, Asp N-G \& Vessby BOH (1999) Improved glycemic control and lipid profile and normalized fibrinolytic activity on a low-glycemic index diet in type 2 diabetic patients. Diabetes Care 22, 10-18.

Jenkins DJ, Jenkins AL, Wolever TMS, Collier GR, Rao AV \& Thompson LU (1987) Starchy foods and fiber: reduced rate of digestion and improved carbohydrate metabolism. Scandinavian Journal of Gastroenterology 22, 132-141.

Jenkins DJ, Wolever TM, Buckley G, Lam KY, Giudici S, Kalmusky J, Jenkins AL, Patten RL, Bird J, Wong GS \& Josse RG (1988) Low-glycemic-index starchy foods in the diabetic diet. American Journal Clinical Nutrition 48, 248-254.

Jenkins DJA, Kendall CWC, Augustin LSA, Franceschi S, Marchie A, Jenkins AL \& Axelsen M (2002) Glycemic index: overview of implications in health and disease. American Journal of Clinical Nutrition 76, 266S-273S.

Jenkins DJA, Wolever TM, Taylor RH, Barker H, Fielden H, Baldwin JM, Bowling AC, Newman HC, Jenkins AL \& Goff DV (1981) Glycemic index of foods: a physiological basis for carbohydrate exchange. American Journal of Clinical Nutrition 34, 362-366.

Kamoi M (1974) Study on metabolism of maltitol. Part 2. Clinical experiments. Journal of the Japanese Diabetes Society 18, 451-460.

Kandelman D (1997) Sugar, alternative sweeteners and meal frequency in relation to caries prevention: new perspectives. British Journal of Nutrition 77, Suppl. 1, S121-S128.
Kaneko T, Kohmoto T, Kikuchi H, Shiota M, Iino H \& Mitsukoka $\mathrm{T}$ (1994) Effects of isomalto-oligosaccharides with different degrees of polymerisation on human fecal bifidobacteria. Bioscience Biotechnology and Biochemistry 58, 2288-2290.

Kaspar L \& Spengler M (1984) Wirkung oraler Gaben von Palatinit auf den Insulinverbrauch bei Typ-I-Diabetikern (Effect of oral doses of Palatinit on insulin requirements in type I diabetics). Aktulle Ernährungsmedizin 9, 60-64.

Kapur A \& Kapur K (2001) Relevance of glycemic index in the management of post-prandial glycaemia. Journal of the Association of the Physicians of India 49, 42-45.

Kawanabe J, Hirasawa M, Takeuchi T, Oda T \& Ikeda T (1992) Noncariogenicity of erythritol as a substrate. Caries Research 26, 358-362.

Kearsley MW, Birch GG \& Lian-Loh RHP (1982) The metabolic fate of hydrogenated glucose syrups. Starch 8, 279-283.

Keller U \& Froesch ER (1972) Vergleichende Untersuchungen über den Stoffwechsel von Xylit, Sorbit und Fruktose beim Menschen (Comparative investigations on the metabolism of xylitol, sorbitol and fructose in humans). Schweizerische Medizinische Wochenschrift 102, 1017-1022.

Keup U \& Püttner J (1974) Serumglucose- und -insulinverlauf bei gesunden Probanden nach einmaliger oraler Palatinit- bzw. Saccharosebelastung (Determination of blood sugar and plasma insulin in healthy patients having orally absorbed an oral dose of palatinit or saccharose). Bayer AG, Pharma-Bericht no. 4781 vom $01 \cdot 07$

Khaw KT, Wareham N, Luben R, Bingham S, Oakes S, Welch A \& Day N (2001) Glycated haemoglobin, diabetes, and mortality in men in Norfolk cohort of European Prospective Investigation of Cancer and Nutrition (EPIC-Norfolk). British Medical Journal 322, 1-6.

Koch T \& Hudson S (2000) Older people and laxative use: literature review and pilot study report. Journal of Clinical Nursing 9, 516-525.

König KG (1990) Changes in the prevalence of dental caries: how much can be attributed to dietary change. Diet, Nutrition and Dental Caries 24, Suppl. 1, 16-18.

Leach SA (1987) Sugar substitutes and remineralisation. Deutsche Zahnarztliche Zeitschrift 42, S135-S138.

Lederle FA, Busch DL, Mattox KM, West MJ \& Aske DM (1990) Cost-effective treatment of constipation in the elderly: a randomised double-blind comparison of sorbitol and lactulose. American Journal of Medicine 89, 597-601.

Lee BM \& Wolever TMS (1998) Effect of glucose, sucrose and fructose on plasma glucose and insulin responses in normal humans: comparison with white bread. European Journal of Clinical Chemistry 52, 924-928.

Levy RD, Segal I, Hassan H \& Saadia R (1994) Stool weight and faecal $\mathrm{pH}$ in two South African populations with a dissimilar colon cancer risk. South African Journal of Surgery 32 , $127-128$

Life Sciences Research Office (1994) The Evaluation of the Energy of Certain Sugar Alcohols Used as Food Ingredients. Bethesda, MD: Life Sciences Research Office, Federation of American Societies for Experimental Biology.

Life Sciences Research Office (1999) Evaluation of the Net Energy Value of Maltitol. Bethesda, MD: Life Sciences Research Office, Federation of American Societies for Experimental Biology.

Liu S, Manson JE, Stampfer MJ, Rexrode KM, Hu FB, Rimm EB $\&$ Willett WC (2000a) Whole grain consumption and risk of ischemic stroke in women: a prospective study. Journal of the American Medical Association 284, 1534-1540.

Liu S, Willett WC, Stumper MY, Hun FIB, Franz M, Sampson L, Heinekens CH \& Manson JED (2000b) A prospective study of dietary glycaemic load, carbohydrate intake, and risk of 
coronary heart disease in US women. American Journal of Clinical Nutrition 71, 1455-1461.

Livesey G (1990a) The impact of the concentration and dose of Palatinit ${ }^{\mathrm{R}}$ in foods and diets on energy value. Food Sciences and Nutrition 42F, 223-243.

Livesey G (1990b) On the energy value of sugar alcohols with the example of isomalt. In International Symposium on Caloric Evaluation of Carbohydrates, pp. 141-164. Kyoto, Japan: The Japan Association of Dietetic and Enriched Foods.

Livesey G (1992) Energy values of dietary fibre and sugar alcohols for man. Nutrition Research Reviews 5, 61-84.

Livesey G (1993) Comments on the methods used to determine the energy values of carbohydrates: dietary fibre, sugar alcohols and other bulking agents. International Journal of Food Sciences and Nutrition 44, 221-241.

Livesey G (2000a) Studies on Isomalt - Published and Unpublished. Wymondham, UK: Independent Nutrition Logic.

Livesey G (2000b) The absorption of stearic acid from triacylglycerols: an inquiry and analysis. Nutrition Research Reviews 13, 185-214.

Livesey G (2001) Tolerance of low-digestible carbohydrates - a general view. British Journal of Nutrition 85, Suppl. 1, S7-S16.

Livesey G (2002a) Thermogenesis associated with fermentable carbohydrate in humans, validity of indirect calorimetry, and implications of dietary thermogenesis for energy requirements, food energy and body weight. International Journal of Obesity 26, $1553-1569$.

Livesey G (2002b) Approaches to health via lowering postprandial glycaemia. British Journal of Nutrition 88, 741-744.

Livesey G, Buss D, Coussement P, Edwards DG, Howlett J, Jones DA, Kleiner JE, Müller D \& Sentko A (2000) Suitability of traditional energy values for novel foods and food ingredients. Food Control 11, 250-289.

Livesey G, Johnson IT, Gee JM, Smith T, Lee WA, Hillan KA, Meyer J \& Turner SC (1993) 'Determination' of sugar alcohol and Polydextrose $\mathrm{R}^{\mathrm{R}}$ absorption in humans by the breath hydrogen $\left(\mathrm{H}_{2} \mathrm{O}\right)$ technique: the stoichiometry of hydrogen production and the interaction between carbohydrates assessed in vivo and in vitro. European Journal of Clinical Nutrition 47, 419-430.

Livesey G, Wilson PDG, Roe MA, Faulks RM, Oram LM, Brown JC, Eagles J, Greenwood RH \& Kennedy H (1998) Splanchnic retention of intraduodenal and intrajejunal glucose in healthy adults. American Journal of Physiology 38, E709-E716.

MacDonald I, Keyser A \& Pacy D (1978) Some effects, in man, of varying the load of glucose, sucrose, fructose or sorbitol on various metabolites in blood. American Journal of Clinical Nutrition 31, 1305-1311.

MacGillivary PC, Finley HVL \& Binns TB (1959) Use of lactulose to create a preponderance of lactobacilli in the intestine of bottle fed infants. Scottish Medical Journal 4, 182-189.

McNaught AD (1996) Nomenclature of carbohydrates (JCBN). Pure and Applied Chemistry 68, 1919-2008. www.chem.qmul. ac.uk/iupac/2carb/

Macpherson G (1990) Black's Medical Dictionary. London: Black A \& C.

McRorie J, Zorich N, Riccardi K, Filloon T, Wason S \& Giannalla R (2000) Effect of olestra and sorbitol consumption on objective measures of diarrhea: impact of stool viscosity on common gastrointestinal symptoms. Regulatory Toxicology and Pharmacology 31, 59-67.

Mäkinen KK, Isotupa KP, Kivilompolo T, Mäkinen PL, Toivanen J \& Soderling E (2001) Comparison of erythritol and xylitol saliva stimulants in the control of dental plaque and mutans streptococci. Caries Research 35, 129-135.

Mäkinen KK, Mäkinen PL, Pape HR, Allen P, Bennett CA, Isokangas PJ \& Isotupa KP (1995) Stabilisation of rampant caries: polyol gum and arrest of dentine caries in two long-term cohort studies in young subjects. International Dental Journal 45, 93-107.

Mäkinen KK, Makinën PL, Pape HR Jr, Peldyak J, Hujoel P, Isotupa KP, Soderling E, Isokangas PJ, Allen P \& Bennett C (1996) Conclusion and review of the Michigan Xylitol Programme (1986-1995) for the prevention of dental caries. International Dental Journal 46, 22-34.

Marteau P \& Flourié B (2001) Tolerance to low-digestible carbohydrates: symptomatology and methods. British Journal of Nutrition 84, Suppl. 1, S17-S21.

Matthews DR, Hosker JP, Rudenski AS, Naylor BA, Treacher DF \& Turner RC (1985) Homeostasis model assessment: insulin resistance and beta-cell function from fasting plasma glucose and insulin concentrations in man. Diabetologia 28, 412-419.

Mehnert H (1971) The relative value of sugar substitutes and artificial sweeteners in the diet of diabetics. Deutsche Gesselschaft für Ernärung 20. Darmstadt: Steinkopff.

Mehnert H, Struhlfauth K, Mehnert B, Weiner L \& Hoelflmayr X (1960) Uber die Moglichkeiten der Verabreichung hoher peroraler Gaben von Fructose, Sorbit oder Fructose/Sorbit-gesmish an Diabetiker (On the possibility of the administration by mouth of fructose, sorbitol or fructose/sorbitol gesmish in diabetics). Müchener Medizin Wochenschrift 102, 1-11.1.

Meyer KA, Kushi LH, Jacobs DR Jr, Slavin J, Sellers TA \& Folsom AR (2000) Carbohydrates, dietary fiber, and incident type 2 diabetes in older women. American Journal of Clinical Nutrition 71, 921-930.

Mimura G, Koga T, Oshikawa K, Kido S, Sadanaga T, Jinnouchi T, Kawagchi K \& Mori N (1972) Maltitol tests with diabetics. Journal of Japanese Nutrition 30, 145-152.

Mital BK \& Garg SK (1995) Anticarcinogenic, hypocholesterolaemic, and antagonistic activities of Lactobacillus acidophilus. Crotatian Review of Microbiology 21, 175-214.

Mitsouka T (1992) Intestinal flora and aging. Nutrition Reviews 50, 438-446.

Morgan LM, Tredger JA, Hampton SM, French AP, Peake JCF \& Marks V (1988) The effect of dietary modification and glycaemia on gastric emptying and gastric inhibitory polypeptide (GIP) secretion. British Journal of Nutrition 60, 29-37.

Mortensen PB, Holtug K \& Rasmmusen HS (1988) Short-chain fatty acid production from mono- and disaccharides in a fecal incubation system: implications for colonic fermentation of dietary fiber in humans. Journal of Nutrition 118, 321-325.

Mühlemann HR (1971) Intra-oral radio telemetry. International Dental Journal 21, 456-465.

Müller-Hess R, Geser CA, Bonjour J-P, Jequier E \& Felber J-P (1975) Effects of oral xylitol administration on carbohydrate and lipid metabolism in normal subjects. Infusiontherapie $\mathbf{2}$, 247-252.

Nasrallah SM \& Iber FL (1969) Mannitol absorption and metabolism in man. American Journal of Medical Sciences 258, $80-88$.

Natah SS, Hussein KR, Touominen JA \& Koivisto VA (1997) Metabolic response to lactitol and xylitol in healthy men. American Journal of Clinical Nutrition 65, 947-950.

National Research Council (1989) Diet and Health: Implications for Reducing Chronic Disease Risk. Washington, DC: Committee on Diet and Health, Food and Nutrition Board. Commission on Life Sciences. National Research Council. National Academy Press.

Newbrun E (1982) Sucrose in the dynamics of the carious process. International Dental Journal 32, 13-23.

Nguyen NU, Dumoulin G, Henriet M-T, Berthelay S \& Regnard J (1993) Carbohydrate metabolism and urinary excretion of calcium and oxalate after ingestion of polyol sweeteners. Journal of Clinical Endocrinology and Metabolism 77, 388-392. 
Nilsson U \& Jägerstad M (1987) Hydrolysis of lactitol, maltitol and Palatinint by human intestinal biopsies. British Journal of Nutrition 58, 199-206.

Noda K, Nakayama K \& Oku T (1994) Serum and insulin levels and erythritol balance after oral administration of erythritol in healthy subjects. European Journal of Clinical Nutrition 48, 286-292.

Nurko S, Baker SS, Colletti RB, Lorenzo CD, Ector W \& Liptak GS (2001) Contemporary pediatrics ${ }^{\circledR}$ archive. www.contpeds. com/past issues/Dec 2001/CME

Oku T \& Noda K (1990) Erythritol balance study and estimation of metabolisable energy of erythritol. In Caloric Evaluation of Carbohydrates, pp. 65-75 [N Hosoya, editor]. Tokyo: Research Foundation for Sugar Metabolism.

Orchard TJ, Dorman JS, Maser RE, Becker DJ, Ellis D, LaPorte RE, Kuller LH, Wolson SK \& Drash AL (1990) Factors associated with avoidance of severe complications after $25 \mathrm{yrs}$ of IDDM: Pittsburgh Epidemiology of Diabetes Complications Study 1. Diabetes Care 13, 741-747.

Ornskov F, Nielsen CB, Nielsen ML \& Christophersen SJ (1988) Peroral mannitol in whole-gut irrigation for chronic constipation in children. Ugeskr Laeger 150, 847-849.

Paige DM, Bayless TM \& Davies LR (1992) Palatinit® (isomalt) digestibility in children. Nutrition Research 12, 27-37.

Pelletier X, Hanesse B, Bornet F \& Derby G (1994) Glycaemic and insulinaemic responses in healthy volunteers upon ingestion of maltitol and hydrogenated glucose syrups. Diabetes and Metabolism 20, 291-296.

Petzoldt R, Lauer P, Spengler M \& Schöffling K (1982a) Palatinit bei typ-II Diabetiken: Wirkung auf blutglucose, seurminsulin, C-peptide und freie Fettsauren im verlagleich mit glucose (Palatinit ${ }^{\circledR}$ in type II diabetics: effect on blood glucose, serum insulin, $\mathrm{C}$ peptide and free fatty acids in comparison with glucose). Deutsche Medizinesche Wochenschrift 107, 1910-1913.

Petzoldt R, Müller-Siebert A, Schöffling K \& Spengler M (1982b) Zur Wirkung von Saccharose, Fruktose und Sorbit auf den Kohlenhydrate-, fett- und Purinstoffwechsel bei Typ II-diabetikern (On the effect of saccharose, fructose and sorbitol on carbohydrate-, fat-, and purine metabolism in type II diabetics). Aktulle Ernährungsmedizin 7, 151-156.

Piche T, Zerbib F, Varannes SB, Cherbut C, Anini Y, Roze C, le Quellec A \& Galmiche JP (2000) Modulation by colonic fermentation of LES function in humans. American Journal of Physiology 278, G578-G584.

Pitzalis G, Deganello F, Mariani P, Chiarini-Testa MB, Virgilii F, Gasparri R, Calvani L \& Bonamico M (1996) Lactitol in chronic idiopathic constipation in children. La Pediatria Medica e Chirurgica 17, 223-226.

Pometta D, Trabichet C \& Spengler M (1985) Effects of a 12week administration of isomalt on metabolic control in type-IIdiabetics. Aktulle Ernährungsmedizin 10, 174-177.

Pontes FA, Silva AT \& Cruz AC (1995) Colonic transit times and the effect of lactulose or lactitol in hospitalized patients. European Journal of Gastroenterology and Hepatology 7, 441-446.

Ponz de Leon M \& Roncucci L (1997) Chemoprevention of colorectal tumors: role of lactulose and of other agents. Scandinavian Journal of Gastroenterology 222, Suppl., 72-75.

Ravelli GP, White A, Spencer R, Hotton P, Harbron C \& Keen R (1995) The effect of lactitol intake upon stool parameters and the faecal bacterial flora in chronically constipated women. Acta Therapeutica 21, 243-255.

Rizkalla SW, Luo J, Wils D, Bruzzo F \& Slama G (2002) Glycaemic and insulinaemic responses to a new hydrogenated starch hydrolysate in healthy and type 2 diabetic subjects. Diabetes and Metabolism 28, 385-390.
Roediger WEW (1990) The starved colon - diminished mucosal nutrition, diminished absorption, and colitis. Diseases of the Colon and Rectum 33, 858-862.

Rolla G, Scheie AA \& Ciardi JE (1985) Role of sucrose in plaque formation. Scandinavian Journal of Dental Research 93, $105-111$.

Roncucci L, Di Donato P, Carati L, Carati L, Ferrari A, Perini M, Bertoni G, Bedogni G, Paris B, Svanoni F, Girola M \& Ponz de Leon M (1993) Antioxidant vitamins or lactulose for the prevention of the recurrence of colorectal adenomas. Colorectal Cancer Study Group of the University of Modena and the Health Care District 16. Diseases of the Colon and Rectum 6, 227-234.

Rowland IR (1991) Nutrition and gut microflora metabolism. In Nutrition, Toxicity and Cancer, pp. 113-136 [IR Rowland, editor]. Boston, MA: CRC Press.

Royal College of General Practitioners (1986) Morbidity Statistics from General Practice - Third National Study, 1981-1982. Series MB5 (1). London: H.M. Stationery Office.

Rugg-Gunn AJ (1989) Lycasin and the prevention of dental caries. In Progress in Sweeteners, pp.311-329 [T Grenby, editor] Amsterdam: Elsevier.

Sacchetta A, Bottini C, Guarisco R, Candiani C \& Brambilla M (2000) Acceptability, efficacy and tolerability of lactitol syrup in chronic or hospitalisation-related constipation. European Bulletin of Drug Research 8, 1-6.

Salford Symposium Consensus (2001) Consensus statements from participants of the International Symposium on Low Digestible Carbohydrates. British Journal of Nutrition 85, Suppl. 1, S5.

Salmerón J, Ascherio A, Rimm EB, Colditz GA, Spiegelman D, Jenkins DJ, Stampfer MJ, Wing AL \& Willet WC (1997a) Dietary fibre, glycaemic load, and risk of NIDDM in men. Diabetes Care 20, 545-550.

Salmerón J, Manson JE, Stampfer MJ, Colditz GA, Wing AL \& Willet WC (1997b) Dietary fibre, glycaemic load, and risk of non-insulin-dependent diabetes in women. Journal of the American Medical Association 277, 472-477.

Salminen S, Salminen E \& Marks V (1982) The effects of xylitol on the secretion of insulin and gastric inhibitory polypeptide in man and rats. Diabetologia 22, 480-482.

Samata A, Burden AC \& Jones GR (1985) Plasma glucose responses to glucose, sucrose, and honey in patients with diabetes mellitus: an analysis of glycaemic and peak incremental indices. Diabetic Medicine 2, 371-373.

Samelson SL, Nelson RL \& Nyhus LM (1985) Protective role of faecal $\mathrm{pH}$ in experimental colon carcinogenesis. Journal of the Royal Society of Medicine 78, 230-233.

Sandler RS, Jordan MC \& Shelton BJ (1990) Demographic and dietary determinants of constipation. American Journal of Public Health 80, 185-189.

Scheie AA, Fejerskov O \& Danielsen B (1998) The effect of xylitol-containing chewing gums on dental plaque and acidogenic potential. Journal of Dental Research 77, 1547-1522.

Scheppach W, Bartram P \& Richer F (1995) Management of diversion colitis, pouchitis and distal ulcerative colitis. In Physiological and Clinical Aspects of Short-chain Fatty Acids, pp. 353-360 [JH Cummings, JL Rombeau and T Sakata, editors]. Cambridge, UK: University Press.

Scheppach W, Luehrs H \& Menzel T (2001) Beneficial health effects of low digestible carbohydrate consumption. British Journal of Nutrition 85, Suppl. 1, S23-S30.

Screvola D, Bottari G, Oberto L, Monzillo V, Perversi L \& Marone P (1993a) Intestinal bacterial toxins and alcohol liver damage: effect of lactitol, a synthetic disaccharide. La Clinica Dietologica 20, 297-314.

Screvola D et al (1993b) The role of lactitol in the regulation of intestinal microflora in liver disease. Giornale di Malattie Infettive e Parassitarie 45, 906-918. 
Secchi A, Pontiroli AE, Cammille L, Bizzi A, Cini M \& Pozza G (1986) Effects of oral administration of maltitol on plasma glucose, plasma sorbitol, and serum insulin levels in man. Klinische Wochenschrift 64, 265-269.

Segal I (1998) Rarity of colorectal adenomas in the African black population. European Journal of Cancer Prevention 7, 387-391.

Segal I (2002) Physiological small bowel malabsorption of carbohydrates protects against bowel diseases in Africans. Journal of Gastroenterology and Hepatology 17, 249-252.

Segal I, Hassan H, Walker AR, Becker P \& Braganza J (1995) Fecal short chain fatty acids in South African urban Africans and whites. Diseases of the Colon and Rectum 38, 732-734.

Sels JP, Verdonk HE \& Wolffenbuttel BH (1998) Effects of acarbose (Glucobay) in persons with type 1 diabetes: a multicentre study. Diabetes Research and Clinical Practice 41, 139-145.

Sheinin A, Makinën KK \& Ylitako K (1974) An intermediate report on the effects of sucrose, fructose and xylitol diets on the caries incidence in man. Acta Odontologica Scandinavia 32, 383-412.

Shively CA, Apgar JL \& Tarka SM (1986) Postprandial glucose and insulin responses to various snacks of equivalent carbohydrate content in normal subjects. American Journal of Clinical Nutrition 43, 335-342.

Signorelli P, Croce P \& Dede A (1996) A clinical study of the use of a combination of glucomannan with lactulose in the constipation of pregnancy. Minerva Ginecologica 48, 577-582.

Sinaud S, Montaurier C, Wils D, Vernet J, Brandolini M, Boutloup-Demange C \& Vermorel M (2002) Net energy value of two low digestible carbohydrates, Lycasin HBC and the hydrogenated polysaccharide constituent of Lycasin HBC in healthy human subjects and their impact on nutrient digestive utilisation. British Journal of Nutrition 87, 131-139.

Slama G (1989) Study of the effects on glycaemia and insulinaemia in normal subject and non-insulin dependent diabetics of three hydrogenated derivatives: Palatinit ${ }^{\circledR}$, Maltisorb® and Lycasin ${ }^{\circledR}$. Hotel-Dieu, Paris: Laboratory Services for Diabetology.

Spengler M, Somogyi JC, Pletcher E \& Boehme K (1987) Tolerability, acceptance and energetic conversion of isomalt (Palatinit) in comparison with sucrose. Aktulle Ernährungsmedizin 12, 210-214.

Staiano A, Simeone D, Del Giudice E, Miele E, Tozzi A \& Toraldo C (2000) Effect of the dietary fiber glucomannan on chronic constipation in neurologically impaired children. Journal of Pediatrics 136, 41-45.

Steinke J, Wood FC, Domage L, Marble A \& Renold AE (1961) Evaluation of sorbitol in the diet camp of diabetic children at camp. Diabetes 10, 218-227.

Stevens J, Levitsky DA, VanSoest PJ, Robertson JB, Kalkwarf HJ \& Roe DA (1987) Effects of psyllium and wheatbran on spontaneous energy intake. American Journal of Clinical Nutrition 46, $812-817$.

Stewart D (2001) Consumption and consumer perceptions: report of a workshop. British Journal of Nutrition 85, Suppl. 1, S61-S62.

Stratton IM, Adler AI, Neil AW, Matthews DR, Manley SE, Cull CA, Hadden D, Turner RC \& Holman RR on behalf of the UK Prospective Diabetes Study Group (2000) Association of glycaemia with macrovascular and microvascular complications of type 2 diabetes (UKPDS 35): prospective observational study. British Medical Journal 321, 405-412.

Sweeney M (1997) Constipation. Diagnosis and treatment. Home Care Provider 2, 250-255.

Sydney University's Glycaemic Index Research Service (2002) Glycaemic Index Report - Isomalt. Sydney, Australia: Sydney University's Glycaemic Index Research Service (SUGiRS), University of Sydney.
Takatsuka T (2000) Influence of Palatinit ${ }^{\circledR}$ and xylitol on demineralisation/remineralisation on bovine enamel. Cariology Today 1, 37-40.

Tarao K, Tamai S, Ito Y, Okawa S \& Hayashi M (1995) On changes in faecal bacteria flora by administration of lactitol in liver cirrhosis patients with hepatic encephalophathy. Journal of the Japanese Society of Gastroenterology 92, 1037-1050.

Teramoto F, Rokutan K, Kawakami Y, Fujimura Y, Uchida J, Oku K, Oku M \& Yoneyama M (1996) Effect of $4^{\mathrm{G}}-\beta$-D-galactosyl sucrose (lactosucrose) on fecal microflora in patients with chronic inflammatory bowel disease. Journal of Gastroenterology 31, 33-39.

Thannhauser SJ \& Meyer KH (1929) Sorbit (Sionin) als Kohlehydraterstz für den Diabeteskranken (Sorbitol (Sionin) as carbohydrate for diabetics). Müchener Medizinische Wochenschrift 76, 356-360.

Thiébaud D, Jacot E, Schmitz H, Spengler M \& Felber JP (1984) Comparative study of isomalt and sucrose by means of continuous indirect calorimetry. Metabolism 33, 808-813.

Thornton JR (1981) High colonic pH promotes colorectal cancer. Lancet i, 1081-1082.

Tong Z-H, Gu W-Z \& Gen Z (1987) Effect on plasma glucose and insulin after xylitol loading in 30 normal adults. Zhonghau Neike Zazhi 26, 420-422.

Toors FA (1992) Chewing gum and dental health - literature review. Revue Belge de Medecine Dentaire 47, 67-92.

Tse PW, Leung SS, Chan T, Sien A \& Chan AK (2000) Dietary fibre intake and constipation in children with severe developmental disabilities. Journal of Paediatric and Child Health 36, 236-239.

Tsuji K, Osada Y, Shimada N, Nishimura R, Kobayashi S, Tomio Ichikawa T \& Hosoya N (1990) Energy value of sorbitol and maltitol in healthy men and rats. In Caloric Evaluation of Carbohydrates, pp. 77-90 [N Hosoya, editor]. Tokyo: Research Foundation for Sugar Metabolism.

Tsunehiro J, Matsukubo T, Shiota M \& Takaesu Y (1997) Effects of a hydrogenated isomaltooligosaccharide mixture on glucan synthesis and on caries development in rats. Bioscience Biochemistry and Biotechnology 61, 2015-2018.

Tucker DM, Sandstead HH, Logan GM, Klevay LM, Mahalko J, Johnson LK, Inman L \& Inglett GE (1981) Dietary fibre and personality factors as determinants of stool output. Gastroenterology 81, 879-883.

Tuohy KM, Kolida S, Lustenberger AM \& Gibson GR (2001) The probiotic effects of biscuits containing partially hydrolysed guar gum and fructo-oligosaccharides - a human volunteer study. British Journal of Nutrition 86, 341-348.

UK Prospective Diabetes Study Group (1998) Intensive bloodglucose control with sulphonylureas or insulin compared with conventional treatment and risk of complications in patients with type 2 diabetes (UKPDS 33). Lancet 352, 837-854.

Unwin N, Shaw J, Zimmet P \& Alberti KGMM (2002) Impaired glucose tolerance and impaired fasting glycaemia: the current status on definition and intervention. Diabetes Medicine 19, 708-723.

Vaaler S, Bjørneklett A, Jelling I, Skrede G, Hannsen K, Fausa O \& Aggenæs $\varnothing$ (1987) Sorbitol as a sweetener in the diet of insulindependent diabetes. Acta Medica Scandinavica 221, 165-170.

Van der Hoeven JS (1979) Influence of disaccharide alcohols on oral microflora. Caries Research 13, 301-306.

Van der Hoeven JS (1980) Cariogenicity of disaccharide alcohol in rats. Caries Research 14, 61-66.

van Es AJH, De Groot L \& Vogt JE (1986) Energy balance of eight volunteers fed on diet supplemented with either lactitol or saccharose. British Journal of Nutrition 56, 545-554.

van Velthuijsen JA (1990) Physiology and metabolic energy of lactitol. In Caloric Evaluation of Carbohydrates, pp. 124-139 [N Hosoya, editor]. Tokyo: Research Foundation for Sugar Metabolism. 
Veitch AM, Kelly P, Segal I, Spies SK \& Farthing MJ (1998) Does sucrase deficiency in black South Africans protect against colonic disease. Lancet 351, 183.

Velazquez OC, Lederer HM \& Rombeau JL (1996) Butyrate and the colonocyte. Implications for neoplasia. Digestive Diseases Science 41, 727-739.

Verina P, Frandina C, Bilotta T, Ricciardi MR, Villotti G \& Fallucca F (1995) Sorbitol malabsorption and non-specific abdominal symptoms in type II diabetics. Metabolism 44, 796-799.

Waaler SM, Assev S \& Rolla G (1992) Xylitol-5-P formation by dental plaque after 12 weeks' exposure to xylitol/sorbitol containing chewing gum. Scandinavian Journal of Dental Research 100, 319-321.

Wallace TM \& Matthews DR (2000) Poor glycaemic control in type 2 diabetes: a conspiracy of disease, suboptimal therapy and attitude. Quarterly Journal of Medicine 93, 369-374.

Wang W, Lee ET, Fabsitz R, Welty TK \& Howard BV (2002) Using $\mathrm{HbA}(1 \mathrm{c})$ to improve efficacy of the American Diabetes Association fasting plasma glucose criterion in screening for new type 2 diabetes in American Indians: the strong heart study. Diabetes Care 25, 1365-1370.

Wang Y-M \& van Eys J (1981) Nutritional significance of fructose and sugar alcohols. Annual Review of Nutrition 1, 437-475.

Warshaw HS \& Powers MA (1999) A search for answers about foods with polyols (sugar alcohols). The Diabetes Educator 25, 307-310, 315, 321 .

Wegener M, Borsch G, Schffstein J, Luerweg C \& Leverkus F (1990) Gastrointestinal disorders in patients with insulin-treated diabetes mellitus. Digestive Diseases 8, 23-26.

Wheeler ML, Finberg SE, Gibson R \& Fineberg N (1990) Metabolic response to oral challenge of hydrogenated starch hydrolysate versus glucose in diabetes. Diabetes Care 13, 733-740.

Willibald-Ettle I \& Schiweck H (1996) Properties and applications of isomalt and other bulk sweeteners. In Advances in Sweeteners, pp. 134-149 [TH Grenby, editor]. London: Blackie Academic \& Professional.

Wolever TM (2000) Dietary carbohydrates and insulin action in humans. British Journal of Nutrition 83, Suppl. 1, S97-S102.

Wolever TM \& Bolognesi C (1996) Source and amount of carbohydrate affect postprandial glucose and insulin in normal subjects. Journal of Nutrition 126, 2798-2806.

Wolever TM \& Jenkins DJ (1986) The use of glycaemic index in predicting the blood glucose response to mixed meals.
American Journal of Clinical Nutrition 43, 167-172.

Wolever TM, Jenkins DJ, Jenkins AL \& Josse RG (1991) The glycaemic index: methodology and clinical implications. American Journal of Clinical Nutrition 54, 846-854.

Wolver TM, Jenkins DJ, Josse RG, Wong GS \& Lee R (1987) The glycaemic index: similarity of values derived in insulin-dependent and non-insulin-dependent diabetic patients. Journal of the American College of Nutrition 6, 295-302.

Wolever TM, Jenkins DJ, Vuksan V, Jenkins AL, Buckley GC, Wong GS \& Josse RG (1992a) Beneficial effects of a low glycaemic index diet in type 2 diabetes. Diabetes Medicine 9 , 451-458.

Wolever TM, Jenkins DJ, Vuksan V, Jenkins AL, Wong GS \& Josse RG (1992b) Beneficial effect of low-glycemic index diet in overweight NIDDM subjects. Diabetes Care 15, 562-564.

Yamagata S, Goto Y, Ohneda A, Anzai M, Kawashima S, Chiba M, Maruhama Y \& Yamauchi Y (1965) Clinical effects of xylitol on carbohydrate and lipid metabolism in diabetes. Lancet ii, 918-921.

Yamagata S, Goto Y, Ohneda A, Anzai M, Kawashima S, Kikuch J, Chiba M, Marumama Y, Yamauchi Y \& Toyota T (1969) Clinical applications of xylitol in diabetics. In Pentoses and Pentitols, pp.316-325 [BL Horecjker, K Lang and Y Takagi, editors]. Berlin: Springer-Verlag.

Zaal J \& Ottenhof A (1977) Influence of Lactitol on Blood Sugar Levels after Sucrose Intake, TNO report R5443. Zeist, The Netherlands: TNO, Centraal Instituut voor Voedingsonderzoek.

Zhong J, Luo BY, Xiang MJ, Liu HW, Zhai ZK, Wang TS \& Craig SAS (2000) Studies on the effects of polydextrose intake on physiologic functions in Chinese people. American Journal of Clinical Nutrition 72, 1503-1509.

Ziesenitz SC \& Siebert G (1987) The metabolism and utilization of polyols and other bulk sweeteners compared with sugars. In Developments in Sweeteners, vol. 3, pp. 109-149 [TH Grenby, editor]. London and Amsterdam: Elsevier Applied Science Publishing.

Zumbé A \& Brinkworth RA (1992) Comparative studies of gastrointestinal tolerance and acceptability of milk chocolate containing either sucrose, isomalt or sorbitol in healthy consumers and type II diabetics. Zeitschrift Ernährungswissschaft $\mathbf{3 1}$ $40-48$.

Zumbé A, Lee A \& Storey D (2001) Technological properties of low digestible carbohydrates. British Journal of Nutrition $\mathbf{8 5}$, Suppl. 1, S31-S45. 
https://doi.org/10.1079/NRR200371 Published online by Cambridge University Press 